\title{
Article Entropy Generation Incorporating $\gamma$-Nanofluids under the
Influence of Nonlinear Radiation with Mixed Convection
}

\author{
Umair Khan ${ }^{1}\left(\mathbb{D}\right.$, Aurang Zaib ${ }^{2}$, Ilyas Khan ${ }^{3, *}$ and Kottakkaran Sooppy Nisar ${ }^{4}$ (D) \\ 1 Department of Mathematics and Social Sciences, Sukkur IBA University, Sukkur 65200, Pakistan; \\ umairkhan@iba-suk.edu.pk \\ 2 Department of Mathematical Sciences, Federal Urdu University of Arts, Science \& Technology, \\ Gulshan-e-Iqbal Karachi 75300, Pakistan; aurangzaib@fuuast.edu.pk \\ 3 Department of Mathematics, College of Science Al-Zulfi, Majmaah University, \\ Al-Majmaah 11952, Saudi Arabia \\ 4 Department of Mathematics, College of Arts and Science, Prince Sattam bin Abdulaziz University, \\ Wadi Al-Dawaser 11991, Saudi Arabia; n.sooppy@psau.edu.sa \\ * Correspondence: i.said@mu.edu.sa
}

Citation: Khan, U.; Zaib, A.; Khan, I.; Nisar, K.S. Entropy Generation Incorporating $\gamma$-Nanofluids under the Influence of Nonlinear Radiation with Mixed Convection. Crystals 2021, 11,400. https://doi.org/10.3390/ cryst 11040400

Academic Editors: Rajratan Basu and Arcady Zhukov

Received: 26 February 2021

Accepted: 31 March 2021

Published: 10 April 2021

Publisher's Note: MDPI stays neutral with regard to jurisdictional claims in published maps and institutional affiliations.

Copyright: (c) 2021 by the authors. Licensee MDPI, Basel, Switzerland. This article is an open access article distributed under the terms and conditions of the Creative Commons Attribution (CC BY) license (https:// creativecommons.org/licenses/by/ $4.0 /)$.

\begin{abstract}
Nanofluids offer the potential to improve heat transport performance. In light of this, the current exploration gives a numerical simulation of mixed convection flow (MCF) using an effective Prandtl model and comprising water- and ethylene-based $\gamma-\mathrm{Al}_{2} \mathrm{O}_{3}$ particles over a stretched vertical sheet. The impacts of entropy along with non-linear radiation and viscous dissipation are analyzed. Experimentally based expressions of thermal conductivity as well as viscosity are utilized for $\gamma-\mathrm{Al}_{2} \mathrm{O}_{3}$ nanoparticles. The governing boundary-layer equations are stimulated numerically utilizing bvp4c (boundary-value problem of fourth order). The outcomes involving flow parameter found for the temperature, velocity, heat transfer and drag force are conferred via graphs. It is determined from the obtained results that the temperature and velocity increase the function of the nanoparticle volume fraction for $\mathrm{H}_{2} \mathrm{O} \backslash \mathrm{C}_{2} \mathrm{H}_{6} \mathrm{O}_{2}$ based $\gamma-\mathrm{Al}_{2} \mathrm{O}_{3}$ nanofluids. In addition, it is noted that the larger unsteady parameter results in a significant advancement in the heat transport and friction factor. Heat transfer performance in the fluid flow is also augmented with an upsurge in radiation.
\end{abstract}

Keywords: time-dependent flow; entropy generation; non-linear radiation; $\gamma$-alumina nanoparticle; MHD; mixed convection

\section{Introduction}

Several industrial processes, such as the growing of crystals, the manufacture of rubber and plastic sheets, paper and glass fiber production, and processes of polymer and metal extrusion are affected by the flow problem with heat transport provoked through stretched sheets; thus, this issues is extremely important. The cooling rate plays a significant role concerning the quality of the finished product through these procedures; where a moving sheet materializes via an incision, as a result, a boundary layer flow (BLF) emerges in the track of the surface progress. Crane [1] scrutinized the 2D steady flow of viscous fluid from a stretched sheet. After this study, the pioneering effort on the flow field through a stretched sheet achieved substantial interest; as a result, an excellent quantity of literature has been engendered on this work [2-9].

In recent times, nanotechnology has magnetized researchers' attention owing to its several distinct applications in the modern era, such as cancer therapy and diagnosis, interfaces in neuroelectronics, chemical production, and molecular and in vivo therapy applications such as kinesis and surgery, etc. In addition, there have been enhancements in the heat transfer in mechanical as well as thermal systems. Several regular fluids (ethylene glycol, oil, polymer solutions, water, etc.) have low thermal conductivity. Thus, augmenting the performance of such heat transport fluids appears imperative to achieve the expectations 
of scientists and researchers. Choi [10] primarily developed the concept of nanofluids for the purpose of augmenting the performance of regular fluids. Sheikholeslami et al. [11] scrutinized forced convective flow with nanofluids from a stretchable sheet with magnetic function. Mutuku and Makinde [12] examined the influences of dual stratification on time-dependent flow from a smooth sheet with nanofluid and magnetic function. The effect of entropy generation (EG) on the thin fluid flow with nanofluids via a stretched cylinder was scrutinized by Khan et al. [13]. Gireesha et al. [14] implemented a KVL (Khanafer-Vafai-Lightstone) model to explore the influence of nanofluids via dusty fluids with Hall effects. Recently, the influences of nanofluids rendering to assorted surfaces have been studied by numerous researchers [15-20].

The alumina nanofluids are another aspect that has recently attracted the attention of researchers due to their application in numerous procedures of cooling [21-26]. The alumina nanofluids are identified in accordance with their dimension, e.g., alpha and gamma aluminize, etc. The surface properties in well-described forms of gamma and eta alumina were examined in [27]. The entropy influence on the flow of ethylene- and water-based $\gamma$-alumina through stretched sheets, as determined using the effective Prandtl model, was explored by Rashidi et al. [28]. The authors claimed that the fluid temperature decelerates owing to effective $\operatorname{Pr}$ and accelerates without effective Pr. A comparative investigation considering $\gamma-\mathrm{Al}_{2} \mathrm{O}_{3}$ with distinct base fluids was scrutinized by Ganesh et al. [29]. They showed that similar nanoparticles have opposite effects on temperature. Moghaieb et al. [30] employed the $\gamma-\mathrm{Al}_{2} \mathrm{O}_{3}$ particles in their research as an engine coolant. Ahmed et al. [31] examined the unsteady radiative flow comprising ethylene- and water-based $\gamma-\mathrm{Al}_{2} \mathrm{O}_{3}$ nanomaterials through a thin slit with magnetic function. Recently, Zaib et al. [32] developed the model of effective Prandtl to examine the mixed convective flow through a wedge by nanofluids. They achieved multiple results for the opposite flow.

The second law of thermodynamics is more consistent than the first law of thermodynamics because of the restriction of the effectiveness of the first law in engineering systems of heat transport. To find the best method for thermal structures, the second law is employed through the curtailing of irreversibility [33,34]. A larger entropy generation (EG) signifies a larger scope of irreversibility. Hence, EG can be utilized to ascertain criteria for the manufacturing of devices in engineering. An assessment of EG can be used to augment the performance of a system [35-41]. In addition, entropy generation can be utilized in analysis of the brain and its diseases from both a psychiatric as well as a neurological perspective. Rashidi et al. [42] examined the stimulus of magnetic function on the fluid flow in a rotated permeable disk with nanofluid. Dalir et al. [43] surveyed the effect of entropy on the force convective flow from a stretching surface containing viscoelastic nanofluid. The Keller-box algorithm was utilized to find the numerical result. Shit et al. [44] discussed the effect of EG on convective magneto flow using nanofluid in porous medium with radiation impact. They employed FDM (finite difference method) along with Newton's technique of linearization. The influences of radiation and viscous dissipation on the flow of copper and silver nanomaterials through a rotated disk with entropy were studied by Hayat et al. [45]. Recently, Shafee et al. [46] scrutinized the stimulus of nanofluid via a tube with entropy generation by involving swirl tools of the flow.

The above-mentioned investigations were dependent on steady- state behavior. However, in certain situations, the flow depends on time, owing to unexpected changes in temperature or the heat-flux of the surface, and as a result, it becomes vital to take timedependent (unsteady) flow conditions into consideration. In addition, the phenomena of time-dependent flow is significant in numerous areas of engineering, such as rotating parts in piston engines, the turbo machinery and aerodynamics of helicopters, etc. Thus, the intention of the current research is to explore the impact of time-dependent mixed convective flow incorporating $\mathrm{H}_{2} \mathrm{O} \backslash \mathrm{C}_{2} \mathrm{H}_{6} \mathrm{O}_{2}$ based $\gamma$-nanofluids. The influences of nonlinear radiation and viscous dissipation with entropy are also analyzed. The Lobatto IIIA formula is used to find the numerical solutions of the transmuted ODEs (ordinary differential equations). 


\section{Mathematical Formulation}

In the mathematical model presented herein, we incorporated the time-dependent 2D mixed convective flow of $\mathrm{H}_{2} \mathrm{O} \backslash \mathrm{C}_{2} \mathrm{H}_{6} \mathrm{O}_{2}$ based $\gamma-\mathrm{Al}_{2} \mathrm{O}_{3}$ nanoparticles through a stretched vertical sheet. The viscous dissipation, non-linear radiation and non-uniform heat source/sink were taken as an extra assumption in the energy equation. It was also presumed that the flow was incompressible and that the nanoparticles and the base fluid were in thermal equilibrium. The applied magnetic field (MF) was taken to be timedependent $B=B_{0} / \sqrt{1-C t}$ and normal to the flow of surface. In addition, there was no polarization effect, and thus the external electric field was presumed to be zero and the magnetic Reynolds number was presumed to be small (in comparison to the applied MF, the induced MF was negligible). The demarcated values of the thermo-physical properties of the aforementioned nanofluids are shown in Table 1.

Table 1. Thermo-physical properties of nanoparticle and base fluids [47].

\begin{tabular}{cccc}
\hline & Water $\left(\mathbf{H}_{\mathbf{2}} \mathbf{O}\right)$ & Ethylene Glycol $\left(\mathbf{C}_{\mathbf{2}} \mathbf{H}_{\mathbf{6}} \mathbf{O}_{\mathbf{2}}\right)$ & Alumina $\left(\mathbf{A l}_{\mathbf{2}} \mathbf{O}_{\mathbf{3}}\right)$ \\
\hline$\rho^{\prime}\left(\mathrm{kg} / \mathrm{m}^{3}\right)$ & 998.3 & 1116.6 & 3970 \\
\hline$c^{\prime}{ }_{p}(\mathrm{~J} / \mathrm{kg}, \mathrm{K})$ & 4182 & 2382 & 765 \\
\hline$k^{\prime}(\mathrm{W} / \mathrm{m}, \mathrm{K})$ & 0.60 & 0.249 & 40 \\
\hline$\beta^{\prime} \times 10^{-5}\left(\mathrm{~K}^{-1}\right)$ & 20.06 & 65 & 0.85 \\
\hline$\sigma^{\prime}(\Omega, \mathrm{m})^{-1}$ & 0.05 & $1.07 \times 10^{-7}$ & $10^{-12}$ \\
\hline $\operatorname{Pr}$ & 6.96 & 204 & - \\
\hline
\end{tabular}

The coordinate system is assumed in Cartesian form $(x, y, t)$, where the $\mathrm{x}$-axis is run along the stretching sheet and the $y$-axis is orthogonal to it; $t$ symbolizes the time. The velocity and temperature at the stretching sheet are respectively presented as $U_{w}=a x /(1-C t)$ and $T_{f}=T_{\infty}+b x^{2} /(1-C t)^{2}$, where $a, b$, are the constants and the capital letter $C$ is used for the decelerated and accelerated sheet when $C<0$ and $C>0$, respectively. Under these hypotheses, the governing equations for the momentum and heat transfer of nanofluids with thermo-physical properties and unsteady boundary layer convective flow can be explained as:

$$
\begin{gathered}
\frac{\partial u_{1}}{\partial x}+\frac{\partial v_{1}}{\partial y}=0 \\
\frac{\partial u_{1}}{\partial t}+v_{1} \frac{\partial u_{1}}{\partial y}+u_{1} \frac{\partial u_{1}}{\partial x}=\frac{\mu^{\prime}{ }_{n f}}{\rho^{\prime}{ }_{n f}} \frac{\partial^{2} u_{1}}{\partial y^{2}}-\frac{\sigma_{n f}^{\prime} B^{2}}{\rho^{\prime}{ }_{n f}} u_{1}+g^{\prime} \frac{\left(\rho^{\prime} \beta^{\prime}\right)_{n f}}{\rho^{\prime}{ }_{n f}}\left(T_{1}-T_{\infty}\right) \\
\frac{\partial T_{1}}{\partial t}+v_{1} \frac{\partial T_{1}}{\partial y}+u_{1} \frac{\partial T_{1}}{\partial x}=\frac{k_{n f}^{\prime}}{\left(\rho^{\prime} c^{\prime}\right)_{n f}} \frac{\partial^{2} T_{1}}{\partial y^{2}}-\frac{1}{\left(\rho^{\prime} c_{p}^{\prime}\right)_{n f}}\left(\frac{\partial q_{r}^{\prime}}{\partial y}\right)+\frac{\mu_{n f}^{\prime}}{\left(\rho^{\prime} c^{\prime}{ }_{p}\right)_{n f}}\left(\frac{\partial u_{1}}{\partial y}\right)^{2}+\frac{Q_{0}}{\left(\rho^{\prime} c_{p}^{\prime}\right)_{n f}}
\end{gathered}
$$

The approximation of Rosseland for the term nonlinear radiative heat flux is given as:

$$
q_{r}^{\prime}=-\frac{4 \sigma^{\prime *}}{3 k^{\prime *}} \frac{\partial T_{1}^{4}}{\partial y}=-\frac{16 \sigma^{\prime *}}{3 k^{\prime *}} T_{1}^{3} \frac{\partial T_{1}}{\partial y}
$$

Utilizing Equation (4) in Equation (3), it can defined as:

$$
\begin{aligned}
& \frac{\partial T_{1}}{\partial t}+v_{1} \frac{\partial T_{1}}{\partial y}+u_{1} \frac{\partial T_{1}}{\partial x}=\frac{k^{\prime}{ }_{n f}}{\left(\rho^{\prime} c^{\prime} p\right)_{n f}} \frac{\partial^{2} T_{1}}{\partial y^{2}}+\frac{16 \sigma^{\prime *} T_{1}^{2}}{3 k^{\prime *}\left(\rho^{\prime} c^{\prime} p\right)_{n f}}\left(T_{1} \frac{\partial}{\partial y}\left(\frac{\partial T_{1}}{\partial y}\right)+3\left(\frac{\partial T_{1}}{\partial y}\right)^{2}\right)+ \\
& \frac{\mu_{n f}^{\prime}}{\left(\rho^{\prime} c^{\prime} p\right)_{n f}}\left(\frac{\partial u_{1}}{\partial y}\right)^{2}+\frac{Q_{0}}{\left(\rho^{\prime} c^{\prime}\right)_{n f}},
\end{aligned}
$$


where the last term represents the erratic heat sink/source and is defined as:

$$
Q_{0}=\frac{k_{f}^{\prime}\left(T_{f}-T_{\infty}\right) U_{w}(x, t)}{x v_{f}^{\prime}}\left(A_{0} f^{\prime}+B_{0}\left(\frac{T_{1}-T_{\infty}}{T_{f}-T_{\infty}}\right)\right)
$$

The boundary conditions are:

$$
\begin{gathered}
-k_{n f}^{\prime} \frac{\partial T_{1}}{\partial y}=h_{f}\left(T_{f}-T_{1}\right), u_{1}=U_{w}(x, t), v_{1}=0, \text { at } y=0, \\
T_{1} \rightarrow T_{\infty}, u_{1} \rightarrow 0 \text { as } y \rightarrow \infty .
\end{gathered}
$$

Here, $T_{1}$ is the temperature, $T_{\infty}$ is the free stream or the cold temperature moving on the right side of the sheet, with a zero free stream velocity, while the left side of the sheet is heated at temperature $T_{f}$ from a hot fluid owing convection, which offers a coefficient of heat transfer $h_{f}$ and comprising the expression of thermo-physical properties revealed in Table 2. The interpretations of the rest of the symbols or notations and the mathematical letters in Equation (1) to Equation (7) are presented in Table 3.

Table 2. Thermo-physical properties of gamma nanofluids.

\begin{tabular}{cccc}
\hline & Symbols & Expressions & Model \\
\hline Effective dynamic viscosity & $\mu^{\prime}{ }_{n f} / \mu^{\prime}{ }_{f}$ & $123 \phi^{2}+7.3 \phi+1$ & $\gamma \mathrm{Al}_{2} \mathrm{O}_{3}-\mathrm{H}_{2} \mathrm{O}$ \\
\hline Effective dynamic viscosity & $\mu^{\prime}{ }_{n f} / \mu^{\prime}{ }_{f}$ & $306 \phi^{2}-0.19 \phi+1$ & $\gamma \mathrm{Al}_{2} \mathrm{O}_{3}-\mathrm{C}_{2} \mathrm{H}_{6} \mathrm{O}_{2}$ \\
\hline $\begin{array}{c}\text { Effective thermal } \\
\text { conductivity }\end{array}$ & $k^{\prime}{ }_{n f} / k^{\prime}{ }_{f}$ & $4.97 \phi^{2}+2.72 \phi+1$ & $\gamma \mathrm{Al}_{2} \mathrm{O}_{3}-\mathrm{H}_{2} \mathrm{O}$ \\
\hline $\begin{array}{c}\text { Effective thermal } \\
\text { conductivity }\end{array}$ & $k^{\prime}{ }_{n f} / k^{\prime}{ }_{f}$ & $28.905 \phi^{2}+2.8273 \phi+1$ & $\gamma \mathrm{Al}_{2} \mathrm{O}_{3}-\mathrm{C}_{2} \mathrm{H}_{6} \mathrm{O}_{2}$ \\
\hline Effective Prandtl number & $\operatorname{Pr}_{n f} / \mathrm{Pr}_{f}$ & $82.1 \phi^{2}+3.95 \phi+1$ & $\gamma \mathrm{Al}_{2} \mathrm{O}_{3}-\mathrm{H}_{2} \mathrm{O}$ \\
\hline Effective Prandtl number & $\operatorname{Pr}_{n f} / \mathrm{Pr}_{f}$ & $254.3 \phi^{2}-3 \phi+1$ & $\gamma \mathrm{Al}_{2} \mathrm{O}_{3}-\mathrm{C}_{2} \mathrm{H}_{6} \mathrm{O}_{2}$ \\
\hline Effective dynamic density & $\rho^{\prime}{ }_{n f}$ & $(1-\phi) \rho^{\prime}{ }_{f}+\phi \rho^{\prime}{ }_{s}$ \\
\hline Heat capacitance & $\left(\rho^{\prime} c^{\prime}\right)_{n f}$ & $(1-\phi)\left(\rho^{\prime} c^{\prime}{ }^{\prime}\right)_{f}+\phi\left(\rho^{\prime} c^{\prime}\right)_{s}$ \\
\hline Thermal expansion & $\left(\rho^{\prime} \beta^{\prime}\right)_{n f}$ & $(1-\phi)\left(\rho^{\prime} \beta^{\prime}\right)_{f}+\phi\left(\rho^{\prime} \beta^{\prime}\right)_{s}$ \\
\hline Electrical conductivity & $\sigma^{\prime}{ }_{n f} / \sigma^{\prime}$ & $\left\{1+\frac{3\left(\sigma_{s}^{\prime} / \sigma_{f}^{\prime}-1\right)}{\left(\sigma_{s}^{\prime} / \sigma_{f}^{\prime}+2\right)-\phi\left(\sigma_{s}^{\prime} / \sigma_{f}^{\prime}-1\right)}\right\}$ \\
\hline
\end{tabular}

Following the non-dimensional similarity variables are:

$$
\begin{aligned}
& u_{1}=a x(1-C t)^{-0.5} F^{\prime}, v_{1}=-\left(v^{\prime} f a(1-C t)^{-0.5}\right)^{\frac{1}{2}} F, \\
& \eta=y\left(\frac{a(1-C t)^{-0.5}}{v_{f}^{\prime}}\right)^{\frac{1}{2}}, \theta=\frac{T_{1}-T_{\infty}}{T_{f}-T_{\infty}} .
\end{aligned}
$$

Using Equation (8) in Equation (2) to Equation (6), along with the boundary condition (7) we get the dimensional form of the momentum equations, as follows:

$$
\left.\begin{array}{r}
\mathrm{K}_{1} F^{\prime \prime \prime}+\left[\mathrm{K}_{2}\left(F F^{\prime \prime}-F^{2}-\varepsilon\left(\frac{\eta}{2} F^{\prime \prime}+F^{\prime}\right)\right)-\mathrm{K}_{3} M F^{\prime}+\mathrm{K}_{4} \lambda \theta\right]=0 \\
\left(\text { for } \gamma \mathrm{Al}_{2} \mathrm{O}_{3}-\mathrm{H}_{2} \mathrm{O}\right)
\end{array}\right\},
$$


Table 3. The list of symbols used and their interpretation.

\begin{tabular}{|c|c|}
\hline Symbols & Interpretation \\
\hline$\left(u_{1}(x, y, t), v_{1}(x, y, t), 0\right)$ & Velocity components \\
\hline$(x, y)$ & Cartesian Coordinates \\
\hline$t$ & Time \\
\hline$F$ & Dimensionless velocity \\
\hline$B$ & Magnetic number \\
\hline$A_{0}>0, B_{0}>0$ & Heat source \\
\hline$A_{0}<0, B_{0}<0$ & Heat sink \\
\hline$g^{\prime}$ & Gravitational acceleration \\
\hline Greek Symbols & Interpretation \\
\hline$\mu_{n f}^{\prime}$ & Dynamic viscosity of nanofluid \\
\hline$\rho_{n f}^{\prime}$ & Density of nanofluid \\
\hline$\sigma_{n f}^{\prime}$ & Electrical conductivity of nanofluid \\
\hline$\left(\rho^{\prime} \beta^{\prime}\right)_{n f}$ & Thermal expansion of nanofluid \\
\hline$\left(\rho^{\prime} c^{\prime}\right)_{n f}$ & Heat capacity of nanofluid \\
\hline$k_{n f}^{\prime}$ & Thermal conductivity of nanofluid \\
\hline$v_{f}^{\prime}$ & Kinematic viscosity \\
\hline$\sigma^{\prime *}$ & Stefan Boltzmann constant \\
\hline$k^{\prime *}$ & Mean absorption constant \\
\hline$\theta(\eta)$ & Dimensionless temperature \\
\hline$\phi$ & Nanoparticle volume fraction \\
\hline Subscript & Interpretation \\
\hline$n f$ & Nanofluid \\
\hline
\end{tabular}

In which:

$$
\begin{aligned}
& \mathrm{K}_{1}=\left(123 \phi^{2}+7.3 \phi+1\right), \mathrm{K}_{2}=\left(1-\phi+\phi\left(\frac{\rho_{s}^{\prime}}{\rho_{f}^{\prime}}\right)\right), \mathrm{K}_{3}=\left[\frac{3 \phi\left(\frac{\sigma_{s}^{\prime}}{\sigma_{f}}-1\right)}{\left(\frac{\sigma_{s}^{\prime}}{\sigma_{f}^{\prime}}+2\right)-\left(\frac{\sigma_{s}^{\prime}}{\sigma_{f}^{\prime}}-1\right) \phi}+1\right], \\
& \mathrm{K}_{4}=(1-\phi)+\phi \frac{\left(\rho^{\prime} \beta^{\prime}\right)_{s}}{\left(\rho^{\prime} \beta^{\prime}\right)_{f}}, \mathrm{~K}_{5}=\left(306 \phi^{2}-0.19 \phi+1\right) .
\end{aligned}
$$

while the corresponding dimensional form of the energy equations for the $\gamma \mathrm{Al}_{2} \mathrm{O}_{3}$ nanoparticle are given as:

$$
\left.\begin{array}{r}
\theta^{\prime \prime}\left[1+\frac{4}{3} R_{d} \mathrm{~K}_{6}\left(1+\left(\theta_{w}-1\right) \theta\right)^{3}\right]+4 R_{d} \mathrm{~K}_{6}\left[\left(1+\left(\theta_{w}-1\right) \theta\right)^{2} \theta^{\prime 2}\left(\theta_{w}-1\right)\right]+ \\
\mathrm{K}_{7}\left\{\left(F \theta^{\prime}-2 F^{\prime} \theta\right)-\varepsilon\left(2 \theta+\frac{\eta}{2} \theta^{\prime}\right)\right\}+\mathrm{K}_{6}\left(A_{0} F^{\prime}+B_{0} \theta\right)+\operatorname{Pr}_{f} \mathrm{~K}_{1} E c\left(F^{\prime \prime}\right)^{2}=0 \\
\left(\text { for } \gamma \mathrm{Al}_{2} \mathrm{O}_{3}-\mathrm{H}_{2} \mathrm{O}\right)
\end{array}\right\},
$$


and the appropriate boundary conditions are:

$$
\begin{aligned}
& \theta^{\prime}(0)=-\mathrm{K}_{6} \xi(1-\theta(0)), F^{\prime}(0)=1, F(0)=0 \text { at } \eta=0, \\
& \theta(\eta) \rightarrow 0, F^{\prime}(\eta) \rightarrow 0 \text { as } \eta \rightarrow \infty \text {. } \\
& \text { (for } \left.\gamma \mathrm{Al}_{2} \mathrm{O}_{3}-\mathrm{H}_{2} \mathrm{O} \text { ) }\right\} \\
& \left.\begin{array}{r}
\theta^{\prime}(0)=-\mathrm{K}_{8} \xi(1-\theta(0)), F^{\prime}(0)=1, F(0)=0 \text { at } \eta=0, \\
\theta(\eta) \rightarrow 0, F^{\prime}(\eta) \rightarrow 0, \text { as } \eta \rightarrow \underset{ }{\infty} \\
\left(\text { for } \gamma \mathrm{Al}_{2} \mathrm{O}_{3}-\mathrm{C}_{2} \mathrm{H}_{6} \mathrm{O}_{2}\right)
\end{array}\right\} .
\end{aligned}
$$

Where:

$$
\begin{aligned}
& \mathrm{K}_{6}=\frac{1}{4.97 \phi^{2}+2.72 \phi+1}, \mathrm{~K}_{7}=\frac{\operatorname{Pr}_{f}\left(1-\phi+\phi\left(\frac{\rho_{s}^{\prime}}{\rho_{f}^{\prime}}\right)\right)\left(82.1 \phi^{2}+3.95 \phi+1\right)}{123 \phi^{2}+7.3 \phi+1}, \\
& \mathrm{~K}_{8}=\frac{1}{28.905 \phi^{2}+2.8273 \phi+1}, \mathrm{~K}_{9}=\frac{\operatorname{Pr}_{f}\left(1-\phi+\phi\left(\frac{\rho^{\prime} \rho_{s}^{\prime}}{\rho_{f}}\right)\right)\left(254.3 \phi^{2}-3 \phi+1\right)}{306 \phi^{2}-0.19 \phi+1} .
\end{aligned}
$$

For the above equations, the interpretations of the various dimensional parameters are given in Table 4 (for Equation (9) to Equation (14)). The remaining two parameters are the local mixed convection parameter (ratio of the Grashof number and Reynolds number) and the convective parameter and are demarcated as follows:

$$
\begin{aligned}
& \lambda=\frac{G r_{x}}{\operatorname{Re}^{2} x}, \operatorname{Re}_{x}=\frac{x U_{w}}{v_{f}^{\prime}}, \\
& G r_{x}=g^{\prime} \beta^{\prime}{ }_{f}\left(T_{f}-T_{\infty}\right) x^{3} / v^{\prime 2}{ }_{f}, B i=\frac{h_{f} \sqrt{v_{f}^{\prime}}(1-C t)}{k_{f}^{\prime} \sqrt{a}}
\end{aligned}
$$

Table 4. The list of parameters used and their values.

\begin{tabular}{ccc}
\hline Name of Parameter & Notation/Symbols & Values \\
\hline Magnetic parameter & $M$ & $\sigma^{\prime}{ }_{f} B_{0}^{2} / \rho^{\prime}{ }_{f} a$ \\
\hline Unsteadiness parameter & $\varepsilon$ & $C / a$ \\
\hline Radiation parameter & $R_{d}$ & $4{\sigma^{\prime *}}^{*} T_{\infty}^{3} / k_{f}^{\prime} k^{\prime *}$ \\
\hline Temperature ratio parameter & $\theta_{w}$ & $T_{f} / T_{\infty}$ \\
\hline Eckert number & $E c$ & $\mu^{\prime}{ }_{f} U_{w}^{2} /\left(c^{\prime}{ }_{p}\right)_{f}\left(T_{f}-T_{\infty}\right)$ \\
\hline
\end{tabular}

In order to find the similarity solution for Equations (9)-(12), it is presumed that [48]

$$
\beta_{f}^{\prime}=m_{1} x^{-1} \text { and } h_{f}=m_{2}(1-C t)^{-0.5}
$$

where $m_{1}, m_{2}$ are the constants.

\section{Engineering Quantities of Interest}

The friction factor and the temperature gradient in mathematical structure are described as:

$$
C_{F}=\frac{\tau_{w}^{\prime}}{\rho_{f}^{\prime} U_{w}^{2}}, N u_{x}=\frac{x q_{w}^{\prime}}{k_{f}^{\prime}\left(T_{f}-T_{\infty}\right)},
$$

The wall shear stress and the heat-flux are expressed as:

$$
\tau_{w}^{\prime}=\mu_{n f}^{\prime}\left(\frac{\partial u_{1}}{\partial y}\right)_{y=0}{ }^{\prime} q_{w}^{\prime}=-k_{f}^{\prime}\left(\frac{k_{n f}^{\prime}}{k_{f}^{\prime}}+\frac{16 \sigma^{\prime *} T_{1}^{3}}{3 k^{\prime *} k_{f}^{\prime}}\right)\left(\frac{\partial T_{1}}{\partial y}\right)_{y=0} .
$$


Utilizing Equation (18) in Equation (17), the dimensionless expressions are:

$$
\left.\begin{array}{r}
C_{F} \operatorname{Re}_{x}^{0.5}=\mathrm{K}_{1} F^{\prime \prime}(0) \\
N u_{x} \operatorname{Re}_{x}^{-0.5}=-\left(\frac{1}{\mathrm{~K}_{6}}+\frac{4}{3} R_{d}\left(1+\left(\theta_{w}-1\right) \theta(0)\right)^{3}\right) \theta^{\prime}(0) \\
\left(\text { for } \gamma \mathrm{Al}_{2} \mathrm{O}_{3}-\mathrm{H}_{2} \mathrm{O}\right)
\end{array}\right\}
$$

\section{Formulation of Entropy}

The volumetric EG (entropy generation) for $\gamma \mathrm{Al}_{2} \mathrm{O}_{3}$ nanoparticles is expressed as:

$$
H_{G}=\frac{k_{f}^{\prime}}{T_{\infty}^{2}}\left[\frac{k^{\prime}{ }_{n f}}{k_{f}^{\prime}}+\frac{16 \sigma^{\prime *} T_{1}^{3}}{3 k^{\prime *} k_{f}^{\prime}}\right]\left(\frac{\partial T_{1}}{\partial y}\right)^{2}+\frac{\mu_{n f}^{\prime}}{T_{\infty}}\left(\frac{\partial u_{1}}{\partial y}\right)^{2}+\frac{\sigma_{n f}^{\prime} B^{2}}{T_{\infty}} u_{1}^{2}
$$

The characteristic EG rate can be written as:

$$
H_{g_{0}}=\frac{k_{f}^{\prime}(\Delta T)^{2}}{L^{2} T_{\infty}^{2}}
$$

By using the ratio of Equations (21) and (22), the EG number is described as:

$$
H_{g}=\frac{H_{G}}{H_{g_{0}}}
$$

Implementing Equation (8) in Equations (21) and (22), we obtain:

$$
\left.\left.\left.\begin{array}{r}
H_{g}=\operatorname{Re}_{L}\left(\frac{1}{\mathrm{~K}_{6}}+\frac{4}{3} R_{d}\left(1+\left(\theta_{w}-1\right) \theta\right)^{3}\right) \theta^{\prime 2}+\frac{\mathrm{Re}_{L} B r}{\Omega} \mathrm{K}_{1}{F^{\prime \prime}}^{2}+\mathrm{K}_{3} \frac{M B r \mathrm{Re}_{L}}{\Omega} F^{2}, \\
\left(\text { for } \gamma \mathrm{Al}_{2} \mathrm{O}_{3}-\mathrm{H}_{2} \mathrm{O}\right)
\end{array}\right\}\right) \begin{array}{r}
\Omega \\
H_{g}=\operatorname{Re}_{L}\left(\frac{1}{\mathrm{~K}_{8}}+\frac{4}{3} R_{d}\left(1+\left(\theta_{w}-1\right) \theta\right)^{3}\right) \theta^{\prime 2}+\frac{\operatorname{Re}_{L} B r}{\Omega} \mathrm{K}_{5}{F^{\prime \prime}}^{2}+K_{3} \frac{M B r \mathrm{Re}_{L}}{\Omega} F^{\prime 2}, \\
\left(\text { for } \gamma \mathrm{Al}_{2} \mathrm{O}_{3}-\mathrm{C}_{2} \mathrm{H}_{6} \mathrm{O}_{2}\right)
\end{array}\right\}
$$

where the parameters $\Omega=\Delta T / T_{\infty}, B r=\mu^{\prime}{ }_{f}\left(U_{w}\right)^{2} / k^{\prime}{ }_{f} \Delta T, \operatorname{Re}_{L}=a L^{2} / v^{\prime}{ }_{f}(1-C t)$ are described as the temperature difference and the Brinkman and Reynolds numbers, respectively.

The assessment of the Bejan Be number is vital in sequence to investigate the heat transfer irreversibility, and range of values is between 0 and 1 . The Be number in dimensionless form is described as:

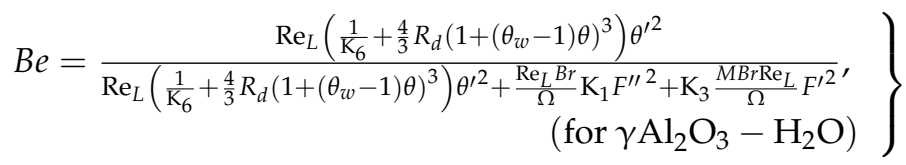

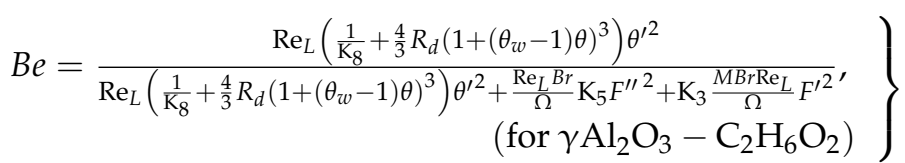

It is concluded from the expressions mentioned above that the irreversibility of fluid friction dominates when $B e$ differs from $0-0.5$, while the heat transport irreversibility dominates when $B e$ differs from $0.5-1$. The value of $B e$ demonstrates that the irreversibility of fluid friction and heat transfer equally contribute to EG. 


\section{Methodology}

The momentum and energy coupled non-linear ODEs (Equations (9) and (10)) and (Equations (11) and (12)), along with the boundary conditions (BCs) in Equation (13) and Equation (14), are solved numerically via bvp4c in MATLAB, which is based on a threestage Lobatto technique for the various comprising parameters and gamma nanofluids. The three-stage Lobatto technique is a collocation technique with fourth-order accuracy. The form of the ODEs (ordinary differential equations), along with the $\mathrm{BCs}$, is altered into the group of first order IVP (intial value problem) by exercising the new variables. This process is carried forward by introducing the following variables:

$$
F=Z_{1}, F^{\prime}=Z_{2}, F^{\prime \prime}=Z_{3}, \theta=Z_{4}, \theta^{\prime}=Z_{5},
$$

Utilizing Equation (28) for the aforementioned ODEs and the boundary conditions, we get a system of ODEs for the model of $\left(\gamma \mathrm{Al}_{2} \mathrm{O}_{3}-\mathrm{H}_{2} \mathrm{O}\right)$ and $\left(\gamma \mathrm{Al}_{2} \mathrm{O}_{3}-\mathrm{C}_{2} \mathrm{H}_{6} \mathrm{O}_{2}\right)$ nanofluids, respectively given as:

$$
\frac{d}{d \eta}\left(\begin{array}{l}
Z_{1} \\
Z_{2} \\
Z_{3} \\
Z_{4} \\
Z_{5}
\end{array}\right)=\left(\begin{array}{l}
Z_{2} \\
Z_{3} \\
\frac{-\left\{K_{2}\left(Z_{1} Z_{3}-Z_{2} Z_{2}-\varepsilon\left(\frac{\eta}{2} Z_{3}+Z_{2}\right)\right)-M K_{3} Z_{2}+K_{4} \lambda Z_{4}\right\}}{K_{1}} \\
\frac{Z_{5}}{-4 R_{d} K_{6}\left(1+\left(\theta_{w}-1\right) Z_{4}\right)^{2}\left(\theta_{w}-1\right) Z_{5} Z_{5}-K_{7}\left(\left(Z_{1} Z_{5}-2 Z_{2} Z_{4}\right)-\varepsilon\left(2 Z_{4}+\frac{\eta}{2} Z_{5}\right)\right)-} \\
\mathrm{K}_{6}\left(A_{0} Z_{2}+B_{0} Z_{4}\right)-\operatorname{Pr}_{f} K_{1} E c Z_{3} Z_{3} \\
\left(1+\frac{4}{3} R_{d} K_{6}\left(1+\left(\theta_{w}-1\right) Z_{4}\right)^{3}\right)
\end{array}\right)
$$

with initial conditions (ICs) as follows:

$$
\left(\begin{array}{l}
Z_{1}(0) \\
Z_{2}(0) \\
Z_{2}(\infty) \\
Z_{5}(0) \\
Z_{4}(\infty)
\end{array}\right)=\left(\begin{array}{l}
0 \\
1 \\
0 \\
-K_{6} \xi\left(1-Z_{4}(0)\right) \\
0
\end{array}\right)
$$

Similarly,

$$
\frac{d}{d \eta}\left(\begin{array}{l}
Z_{1} \\
Z_{2} \\
Z_{3} \\
Z_{4} \\
Z_{5}
\end{array}\right)=\left(\begin{array}{l}
Z_{2} \\
Z_{3} \\
\frac{-\left\{K_{2}\left(Z_{1} Z_{3}-Z_{2} Z_{2}-\varepsilon\left(\frac{\eta}{2} Z_{3}+Z_{2}\right)\right)-M K_{3} Z_{2}+K_{4} \lambda Z_{4}\right\}}{K_{5}} \\
Z_{5} \\
\frac{\left\{\begin{array}{l}
-4 R_{d} K_{8}\left(1+\left(\theta_{w}-1\right) Z_{4}\right)^{2}\left(\theta_{w}-1\right) Z_{5} Z_{5}-K_{9}\left(\left(Z_{1} Z_{5}-2 Z_{2} Z_{4}\right)-\varepsilon\left(2 Z_{4}+\frac{\eta}{2} Z_{5}\right)\right)- \\
K_{8}\left(A_{0} Z_{2}+B_{0} Z_{4}\right)-\operatorname{Pr}_{f} K_{5} E c Z_{3} Z_{3}
\end{array}\right.}{\left(1+\frac{4}{3} R_{d} K_{8}\left(1+\left(\theta_{w w}-1\right) Z_{4}\right)^{3}\right)}
\end{array}\right),
$$

with the corresponding (ICs) as follows:

$$
\left(\begin{array}{l}
Z_{1}(0) \\
Z_{2}(0) \\
Z_{2}(\infty) \\
Z_{5}(0) \\
Z_{4}(\infty)
\end{array}\right)=\left(\begin{array}{l}
0 \\
1 \\
0 \\
-K_{8} \xi\left(1-Z_{4}(0)\right) \\
0
\end{array}\right)
$$

The use of an efficient estimation for $F^{\prime \prime}(0)$ and $\theta^{\prime}(0)$ until the boundary restriction is reached addresses these equations. The step size is fixed to $\Delta \eta=0.01$, which is sufficient to achieve the graphical and the numerical result in tabular form. The range is taken to be $\eta_{\max }=10$, where the finite value of the dimensional variable $\eta$ for the boundary 
restrictions is $\eta_{\max }$. The convergence criteria and the accuracy of the outcomes in all cases are up to level $10^{-10}$.

\section{Results and Discussion}

The impacts of numerous pertinent parameters on the temperature, velocity, heat transfer and drag force are discussed and presented in tabular form and as well as graphically (see Figures 1-21). Table 5 shows the assessment of $-F^{\prime \prime}(0)$ with current outcomes through the outcomes reported by Shafie [49] and Chamkha [50].

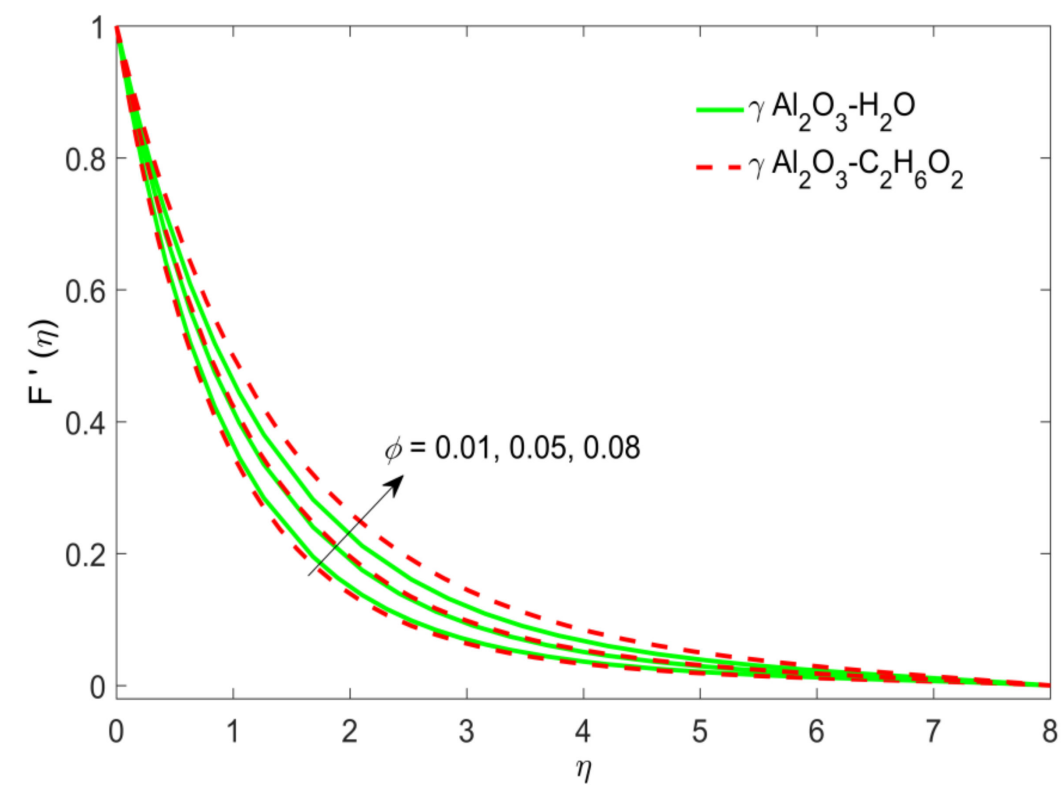

Figure 1. Impact of $\phi$ on $F^{\prime}(\eta)$.

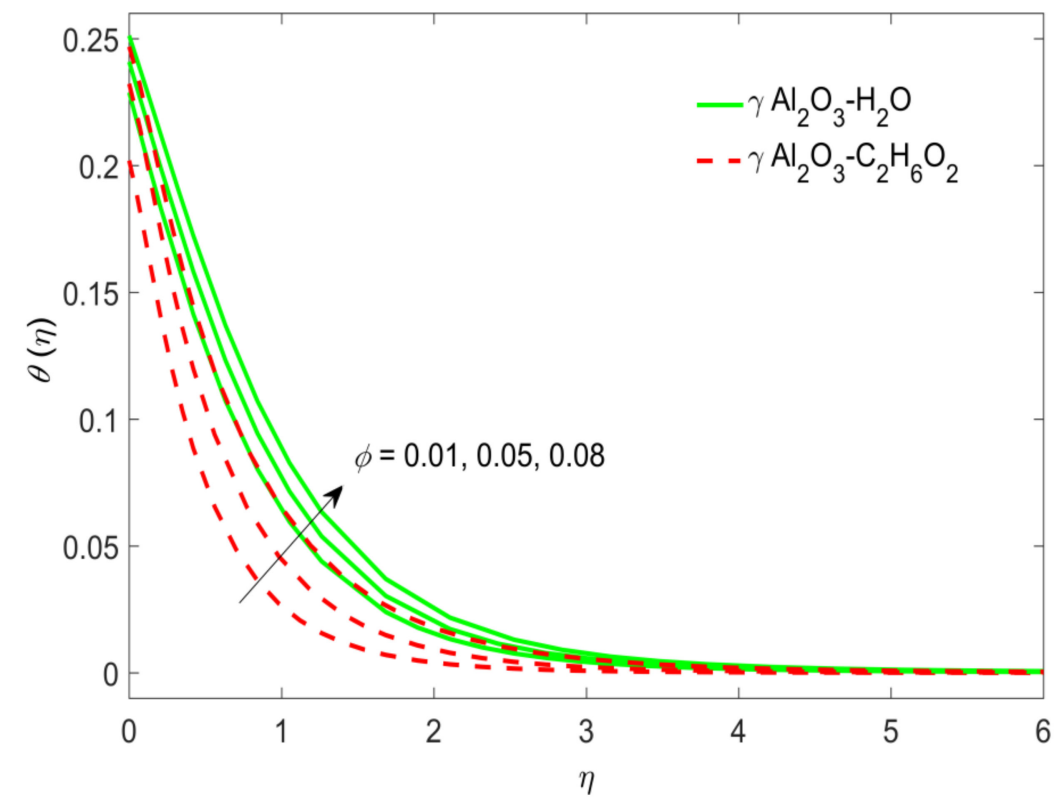

Figure 2. Impact of $\phi$ on $\theta(\eta)$.

The outcomes depict a superb conformity. The significant parameters for computational purposes are considered as $\phi=0.02, M=0.1, \varepsilon=10, \xi=0.5, \theta_{w}=0.1, E c=0.5$, $A_{0}=B_{0}=0.1$ and $R_{d}=02$, with the variations shown in Figures 1-21. 
Figures 1 and 2 describe the influence of volume fraction $\phi$ on the velocity $F^{\prime}(\eta)$ and fluid temperature $\theta(\eta)$. Figures 1 and 2 confirm that the $F^{\prime}(\eta)$ and $\theta(\eta)$ accelerate gradually for larger values of $\phi$. Physically, the nanofluid density under consideration decreases due to the larger amount of $\phi$, which consequently augments the velocity and temperature. Thus, the inter-molecular forces between the particles of nanofluids become weaker, and as a result, the fluid velocity accelerates. It is also clear from Figure 2 that the temperature is higher in the case of water and lower in case of ethylene glycol. The justification for this result is that water has a smaller Prandtl number than ethylene glycol, and as a result, the water thermal diffusivity is much superior to that of ethylene glycol. In addition, $\mathrm{C}_{2} \mathrm{H}_{6} \mathrm{O}_{2}$ nanoliquids can be utilized for the purpose of cooling.

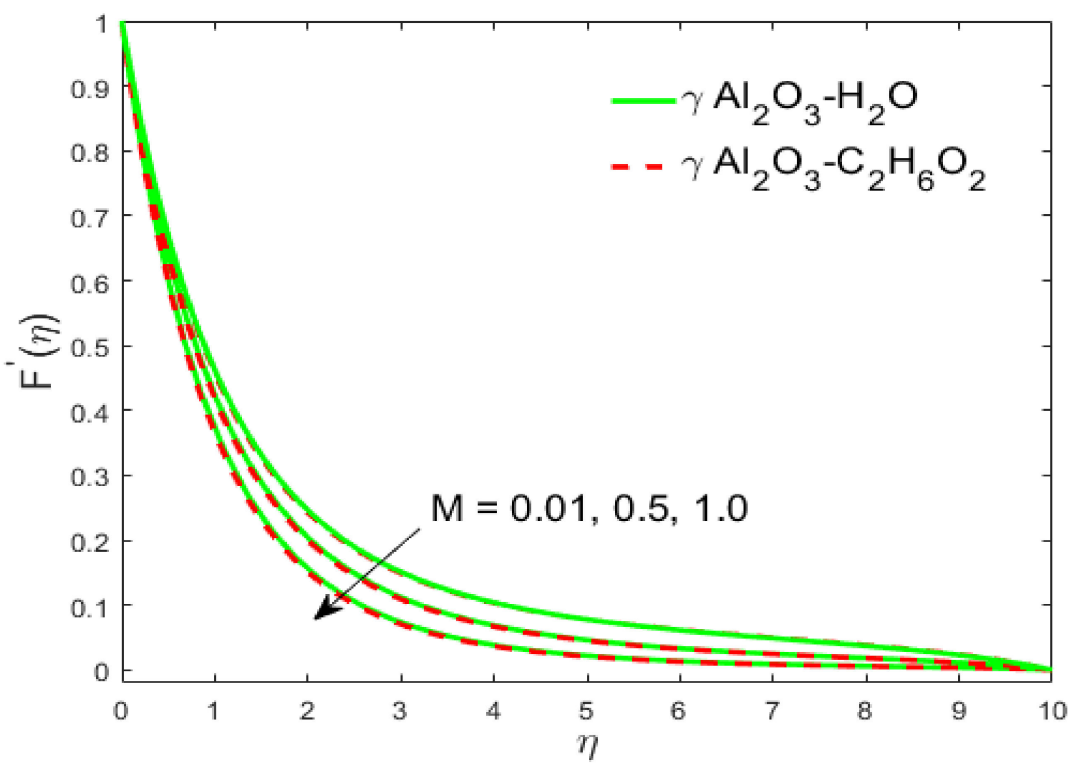

Figure 3. Impact of $M$ on $F^{\prime}(\eta)$.

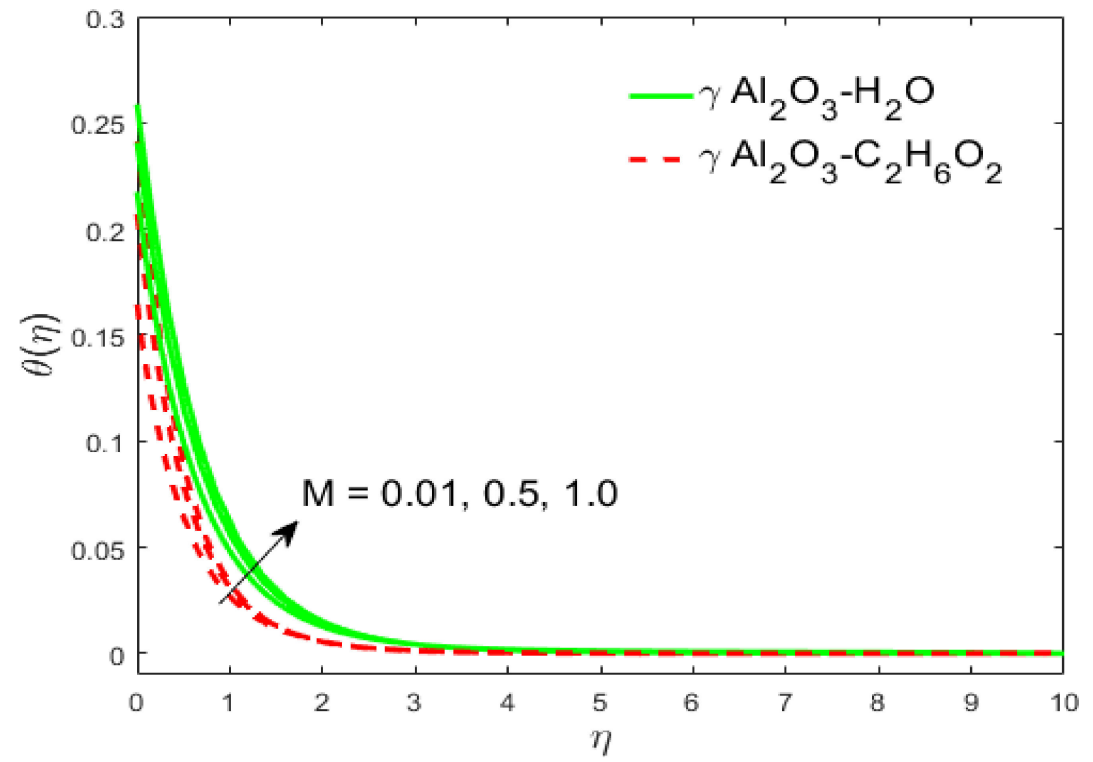

Figure 4. Impact of $M$ on $\theta(\eta)$. 


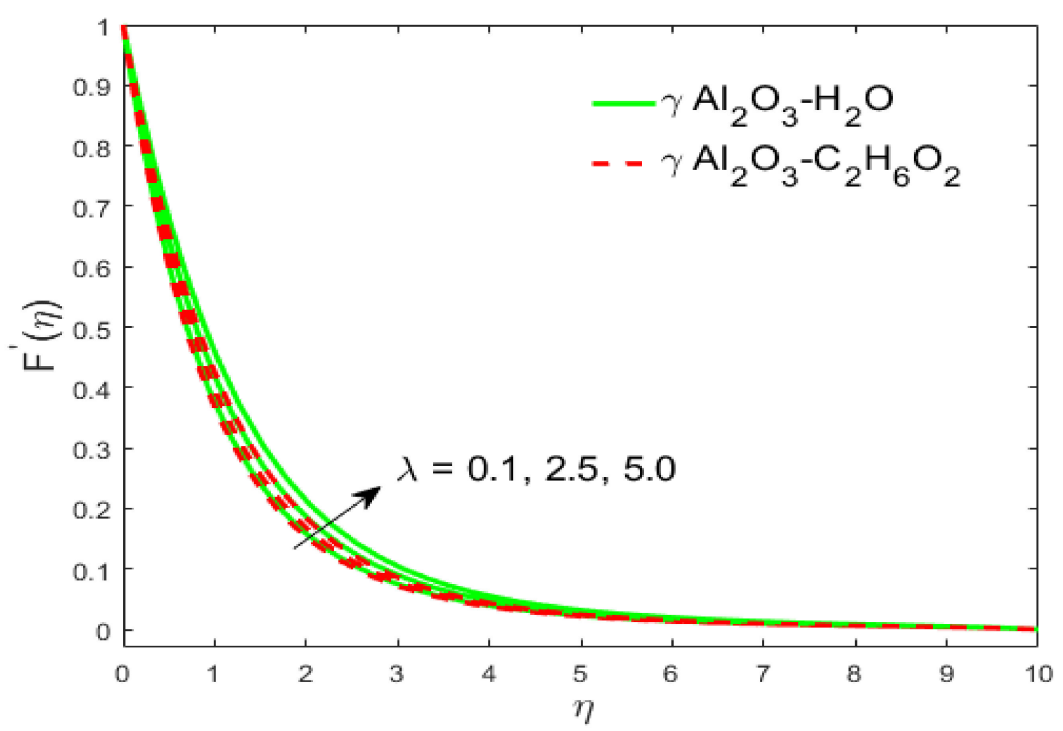

Figure 5. Impact of $\lambda>0$ on $F^{\prime}(\eta)$.

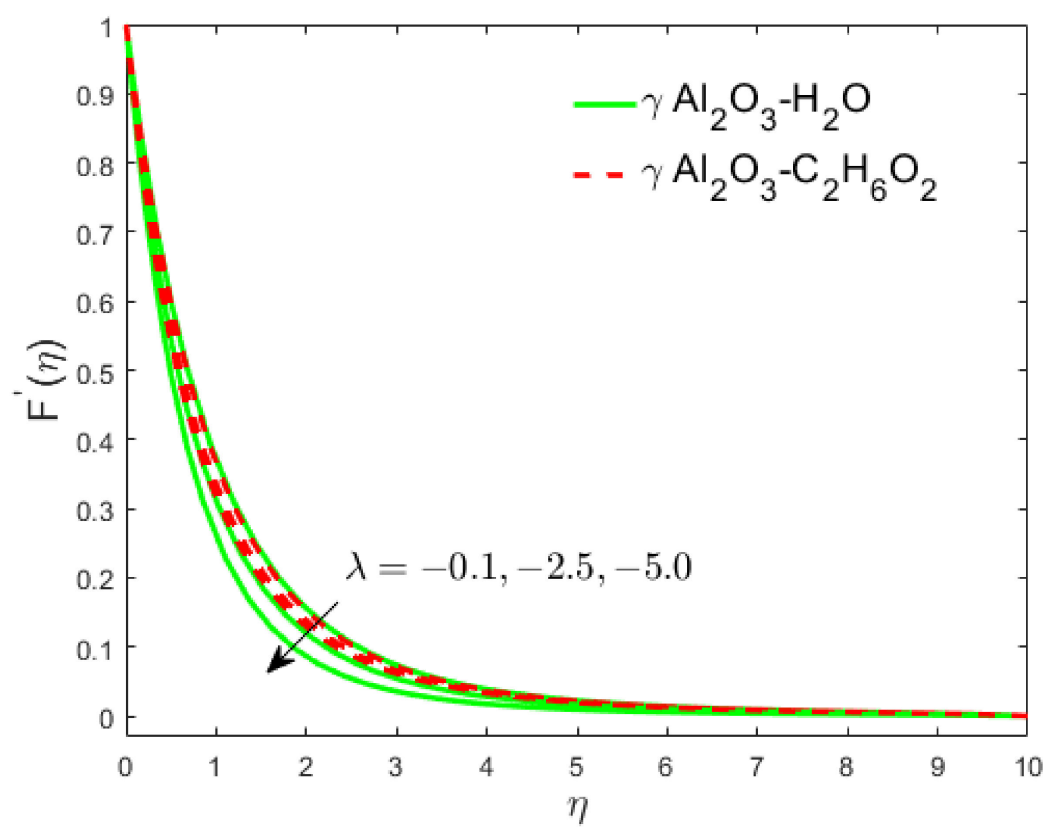

Figure 6. Impact of $\lambda<0$ on $F^{\prime}(\eta)$.

Table 5. Comparison of the values of $-F^{\prime \prime}(0)$, when $M=\phi=\lambda=0$.

\begin{tabular}{cccc}
\hline$\varepsilon$ & Shafie et al. [49] & Chamkha et al. [50] & Current Results \\
\hline 0.8 & 1.261042 & 1.261512 & 1.2610 \\
\hline 1.2 & 1.377722 & 1.378052 & 1.3777 \\
\hline
\end{tabular}

The influence of $M$ on $F^{\prime}(\eta)$ and $\theta(\eta)$ is portrayed in Figures 3 and 4 . Figure 3 suggests that the velocity declines due to $M$ in both $\mathrm{H}_{2} \mathrm{O} \backslash \mathrm{C}_{2} \mathrm{H}_{6} \mathrm{O}_{2}$ based nanofluids.

Physically, the existence of magnetic function engenders a type of resistive force (or Lorentz force) in the flow region, which holds the nanofluid motion. In contrast, the temperature profile (Figure 4 ) rises as a result of $M$. The physics behind this are that an enhancement in magnetic function causes an upsurge in electro-magnetic force, which controls the motion of fluid and consequently increases the temperature as well 
as the thickness. Figures 5-8 show the impact of $\lambda$ on $F^{\prime}(\eta)$ and $\theta(\eta)$ for assisting and opposing flows.

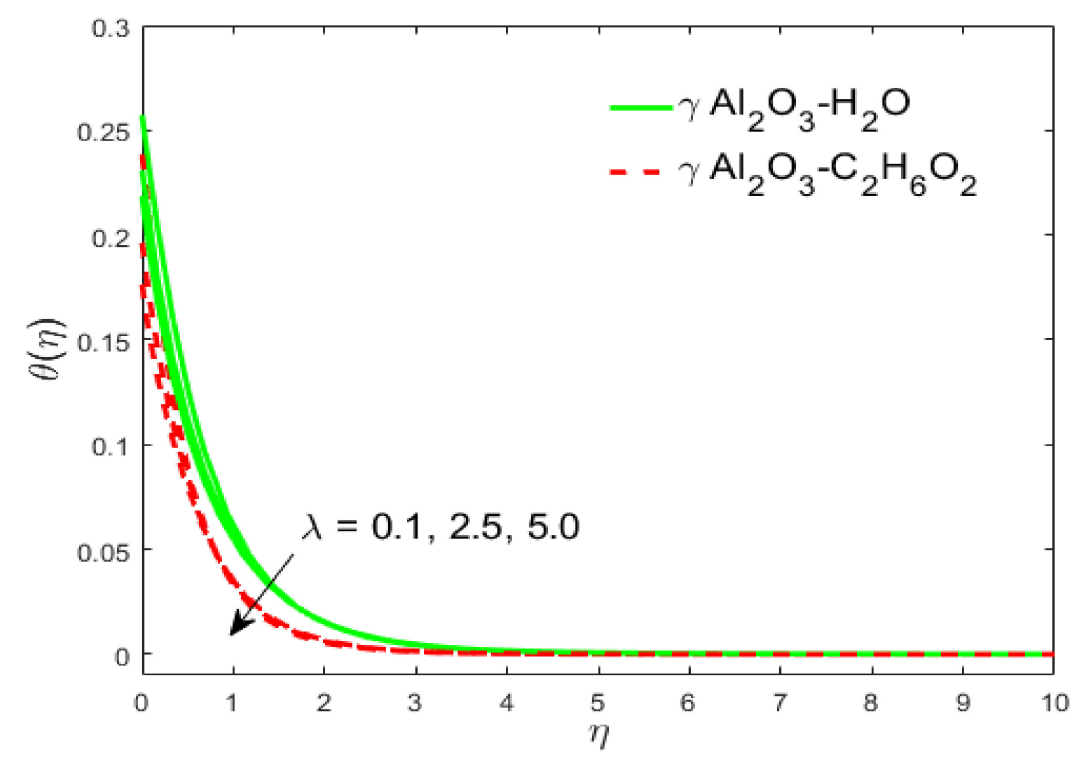

Figure 7. Impact of $\lambda>0$ on $\theta(\eta)$.

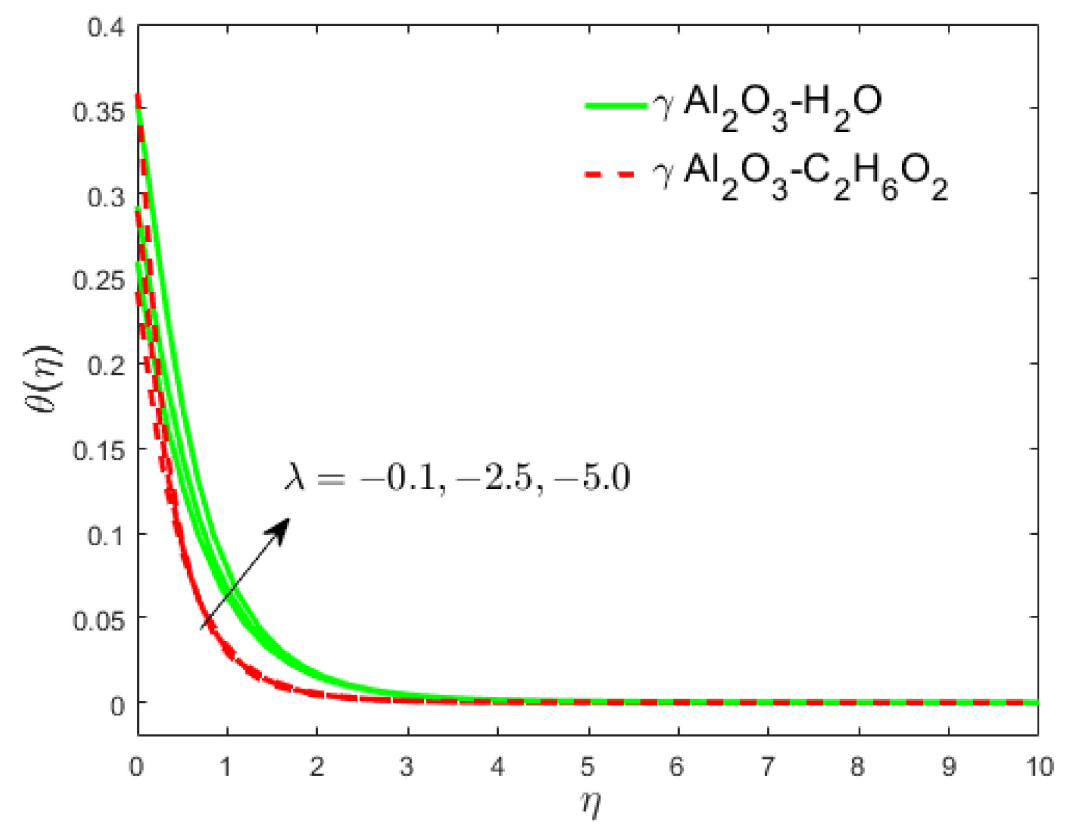

Figure 8. Impact of $\lambda<0$ on $\theta(\eta)$.

It is clear from Figure 5 that the velocity increases with $\lambda$ in the assisting flow, while the velocity as shown in Figure 6 declines in the opposing flow. Physically, a greater amount of $\lambda$ generates a substantial buoyancy force that ultimately generates greater kinetic energy. The reverse is true for the opposing flow. Figure 7 shows that the temperature diminishes due to $\lambda$ for assisting flow in both $\gamma \mathrm{Al}_{2} \mathrm{O}_{3}-\mathrm{H}_{2} \mathrm{O}$ and $\gamma \mathrm{Al}_{2} \mathrm{O}_{3}-\mathrm{C}_{2} \mathrm{H}_{6} \mathrm{O}_{2}$ nanofluids, whereas the temperature increases in the opposing flow, as depicted in Figure 8. Physically, the fluid attains the heat from the sheet, and later on, heat energy is transmuted into different forms of energy, like kinetic energy. As expected, the temperature is lower for $\gamma \mathrm{Al}_{2} \mathrm{O}_{3}-\mathrm{C}_{2} \mathrm{H}_{6} \mathrm{O}_{2}$ than $\gamma \mathrm{Al}_{2} \mathrm{O}_{3}-\mathrm{H}_{2} \mathrm{O}$ due to the greater Prandtl number. The nature of the temperature profiles is observed in Figures 9-11 for changed values of $R_{d}, E c$ and $\xi$. 
Figure 9 confirms that temperature increases with $R_{d}$ for $\mathrm{H}_{2} \mathrm{O} \backslash \mathrm{C}_{2} \mathrm{H}_{6} \mathrm{O}_{2}$ based $\gamma-\mathrm{Al}_{2} \mathrm{O}_{3}$ nanofluids. The coefficient of absorption declines as radiation increases, and due to this, an enhancement occurs in the temperature distribution. Similar behavior is noticed for the Eckert number, owing to fractional heating as illustrated in Figure 10. Larger inference of $E_{c}$ implies that the heat of thermal dissipation is stocked in the fluid, which ultimately increases the temperature. The convective parameter causes upsurges in the distribution of temperature (Figure 11) for $\mathrm{H}_{2} \mathrm{O} \backslash \mathrm{C}_{2} \mathrm{H}_{6} \mathrm{O}_{2}$ based $\gamma-\mathrm{Al}_{2} \mathrm{O}_{3}$ nanofluids.

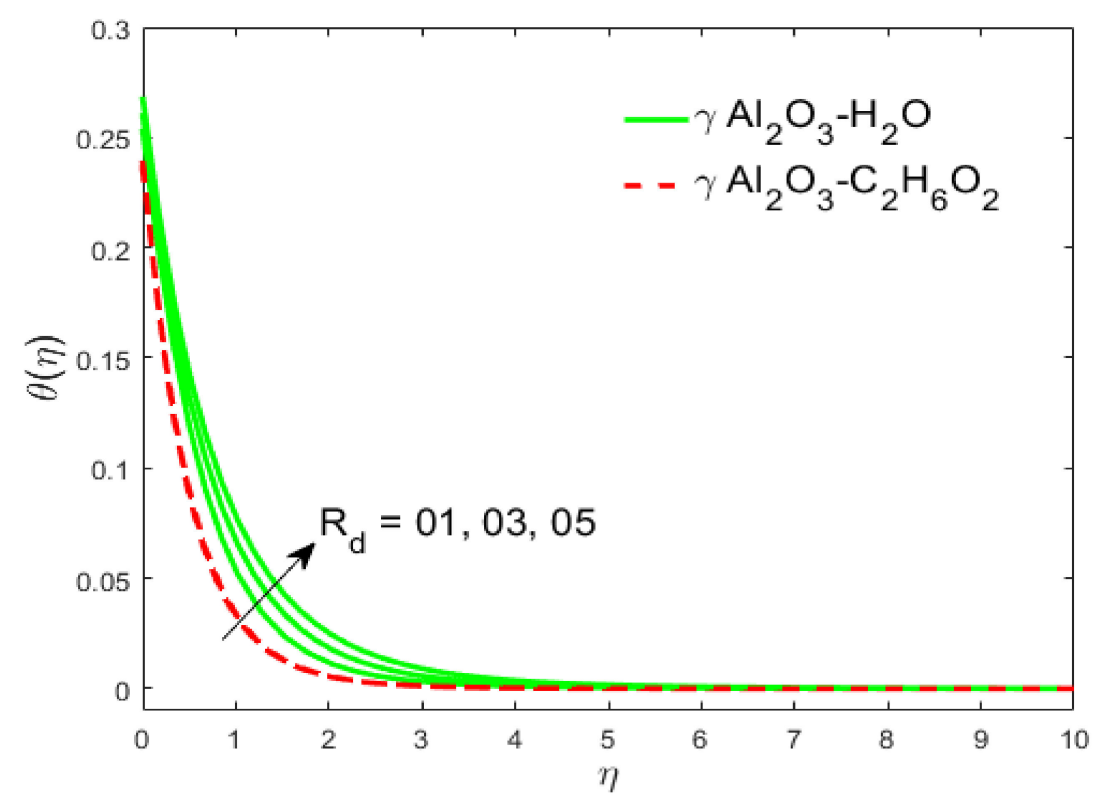

Figure 9. Impact of $R_{d}$ on $\theta(\eta)$.

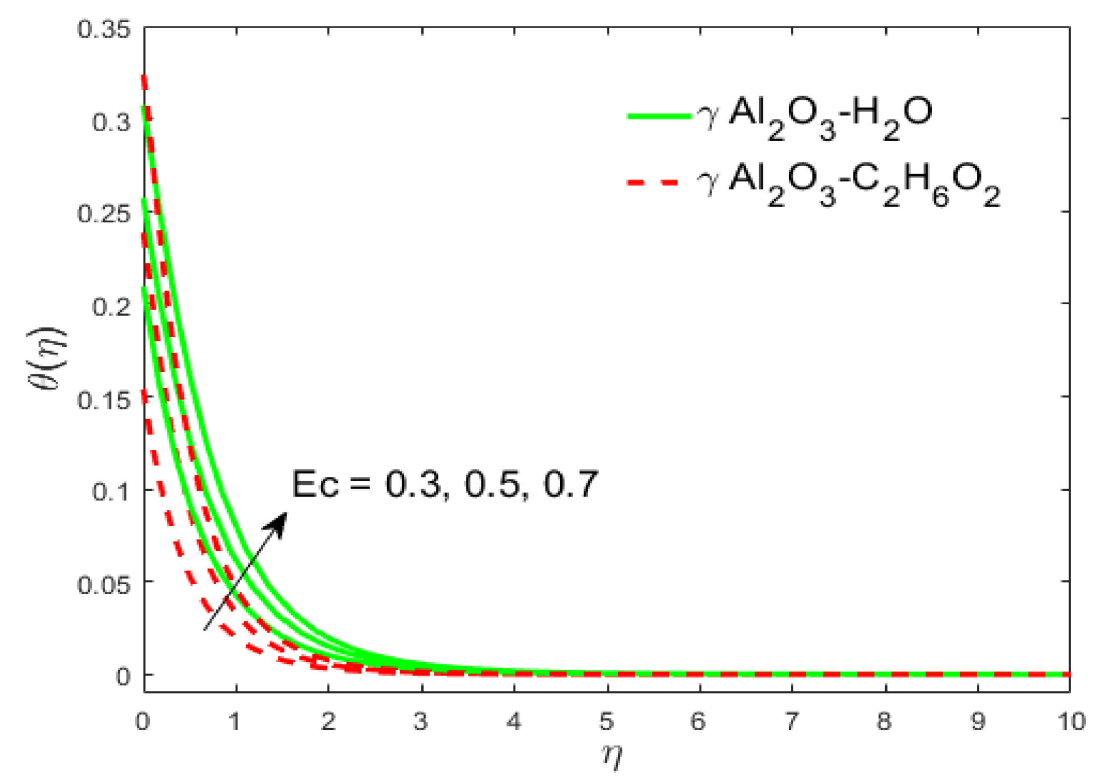

Figure 10. Impact of $E_{c}$ on $\theta(\eta)$.

The sheet temperature gradient increases due to commanding convective heating. This permits the thermal influence to penetrate deeper in the sluggish fluid. Thus, the temperature increases. Figures 12 and 13 demonstrate the influence of heat sink/source on the $\theta(\eta)$ profile. It is clear from these profiles that the heat source increases the temperature, while the heat sink reduces the temperature, as expected. 
Physically, the impact of the heat source $\left(\mathrm{A}_{0}>0, \mathrm{~B}_{0}>0\right)$ adds extra energy within the boundary layer, which ultimately increases the temperature, while the heat sink $\left(\mathrm{A}_{0}<0, \mathrm{~B}_{0}<0\right)$ absorbs the energy, which causes a reduction in the temperature.

Figures 14-16 illustrate the behavior of entropy generation for distinct parameters $\phi$, $\operatorname{Re}_{L}$ and $\mathrm{Br}$ for $\mathrm{H}_{2} \mathrm{O} \backslash \mathrm{C}_{2} \mathrm{H}_{6} \mathrm{O}_{2}$ based $\gamma-\mathrm{Al}_{2} \mathrm{O}_{3}$ nanofluids. Figure $14 \mathrm{a}, \mathrm{b}$ show that the entropy increases due to $\phi$ in both nanofluids. It is interesting to note that ethylene-glycolbased nanofluid has greater impact on the entropy due to the huge Prandtl number and lower thermal diffusivity. Figure $15 \mathrm{a}, \mathrm{b}$ suggest that the entropy enhances due to $\operatorname{Re}_{L}$ in both nanofluids owing to friction nanofluid and heat transport within the boundary layer for $\gamma \mathrm{Al}_{2} \mathrm{O}_{3}-\mathrm{C}_{2} \mathrm{H}_{6} \mathrm{O}_{2}$ and as well as $\gamma \mathrm{Al}_{2} \mathrm{O}_{3}-\mathrm{H}_{2} \mathrm{O}$ nanofluids. Similarly, the impact of $\gamma \mathrm{Al}_{2} \mathrm{O}_{3}-\mathrm{C}_{2} \mathrm{H}_{6} \mathrm{O}_{2}$ on the entropy is greater than $\gamma \mathrm{Al}_{2} \mathrm{O}_{3}-\mathrm{H}_{2} \mathrm{O}$. Figure $16 \mathrm{a}$, b confirm that the entropy depicts the growing function of $\mathrm{Br}$ due to fluid friction for both nanofluids.

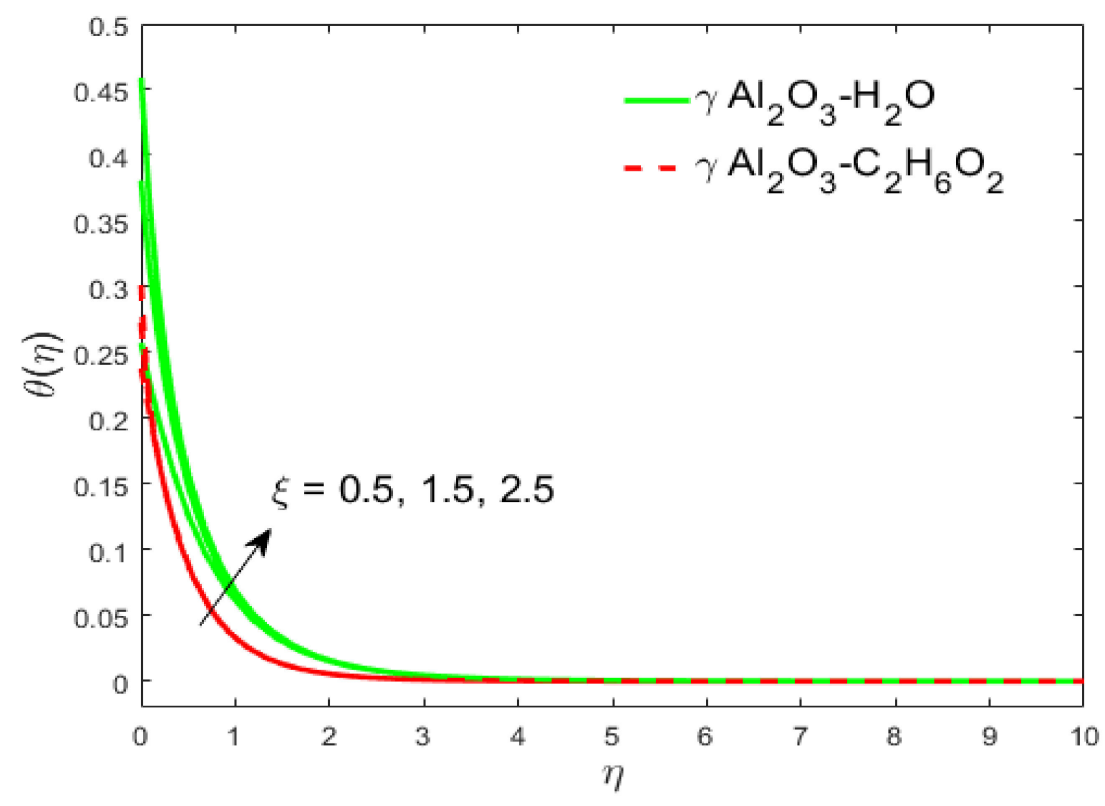

Figure 11. Impact of $\xi$ on $\theta(\eta)$.

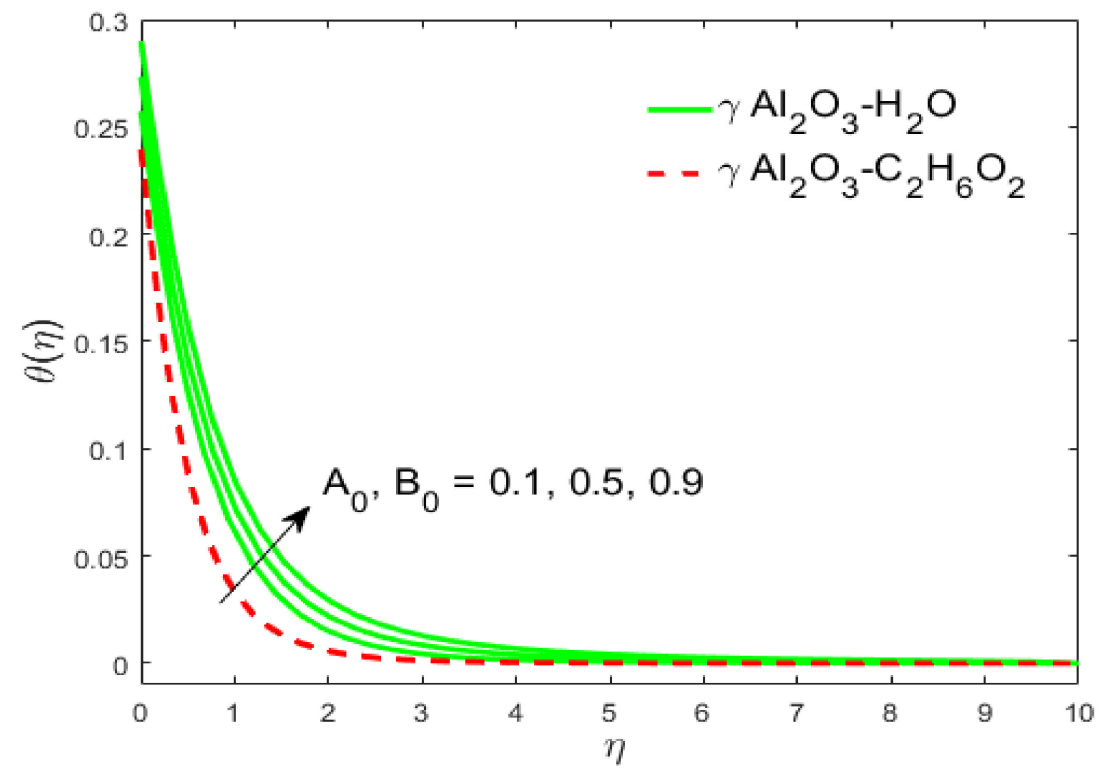

Figure 12. Impact of $\mathrm{A}_{0}>0, \mathrm{~B}_{0}>0$ on $\theta(\eta)$. 


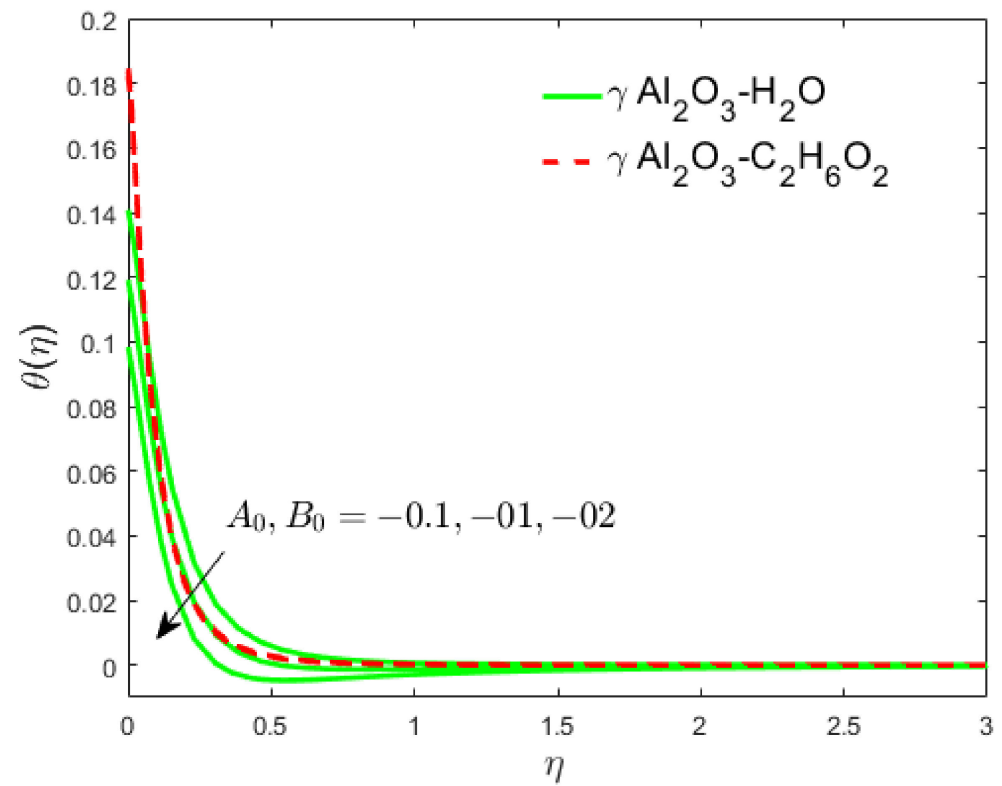

Figure 13. Impact of $\mathrm{A}_{0}<0, \mathrm{~B}_{0}<0$ on $\theta(\eta)$.

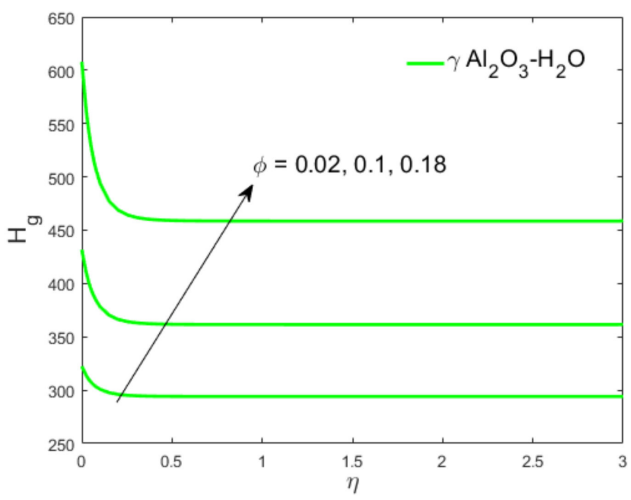

(a)

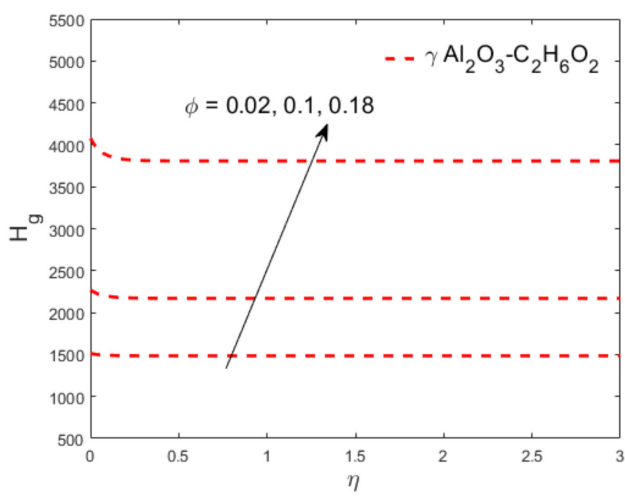

(b)

Figure 14. Impact of $\phi$ on $\mathrm{EG}(\mathbf{a}) \gamma-\mathrm{Al}_{2} \mathrm{O}_{3}-\mathrm{H}_{2} \mathrm{O}$; (b) $\gamma-\mathrm{Al}_{2} \mathrm{O}_{3}-\mathrm{C}_{2} \mathrm{H}_{6} \mathrm{O}_{2}$.

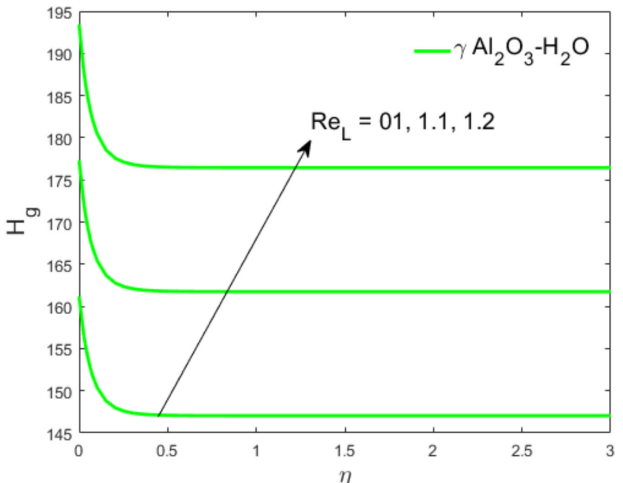

(a)

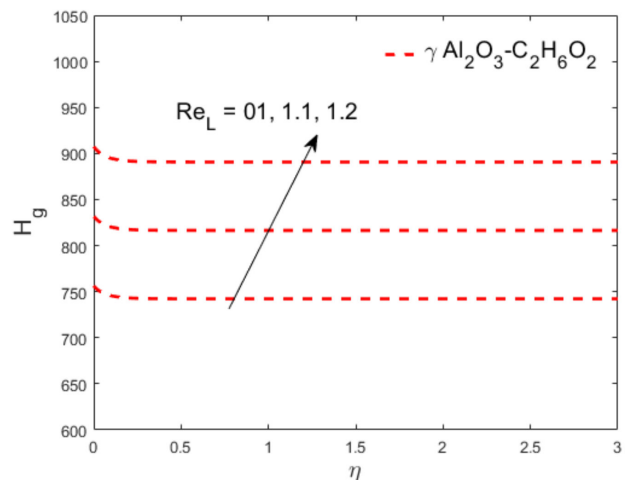

(b)

Figure 15. Impact of $\operatorname{Re}_{L}$ on EG (a) $\gamma-\mathrm{Al}_{2} \mathrm{O}_{3}-\mathrm{H}_{2} \mathrm{O}$; (b) $\gamma-\mathrm{Al}_{2} \mathrm{O}_{3}-\mathrm{C}_{2} \mathrm{H}_{6} \mathrm{O}_{2}$. 


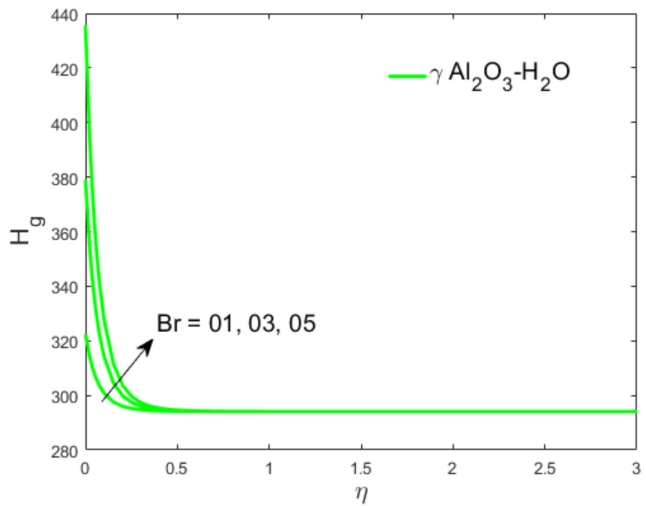

(a)

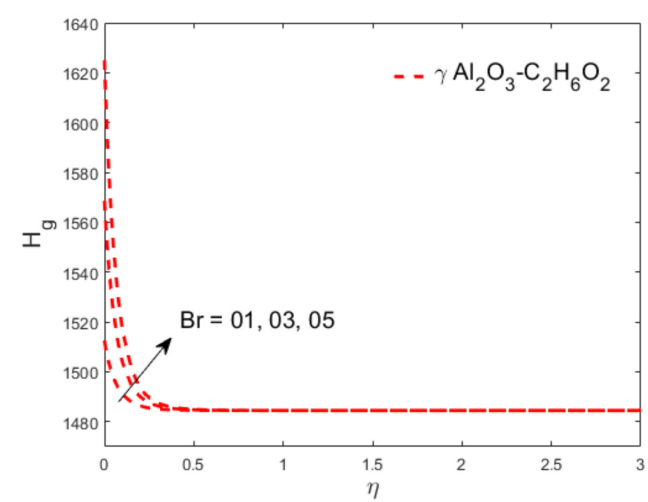

(b)

Figure 16. Impact of $\mathrm{Br}$ on EG. (a) $\gamma-\mathrm{Al}_{2} \mathrm{O}_{3}-\mathrm{H}_{2} \mathrm{O}$; (b) $\gamma-\mathrm{Al}_{2} \mathrm{O}_{3}-\mathrm{C}_{2} \mathrm{H}_{6} \mathrm{O}_{2}$.

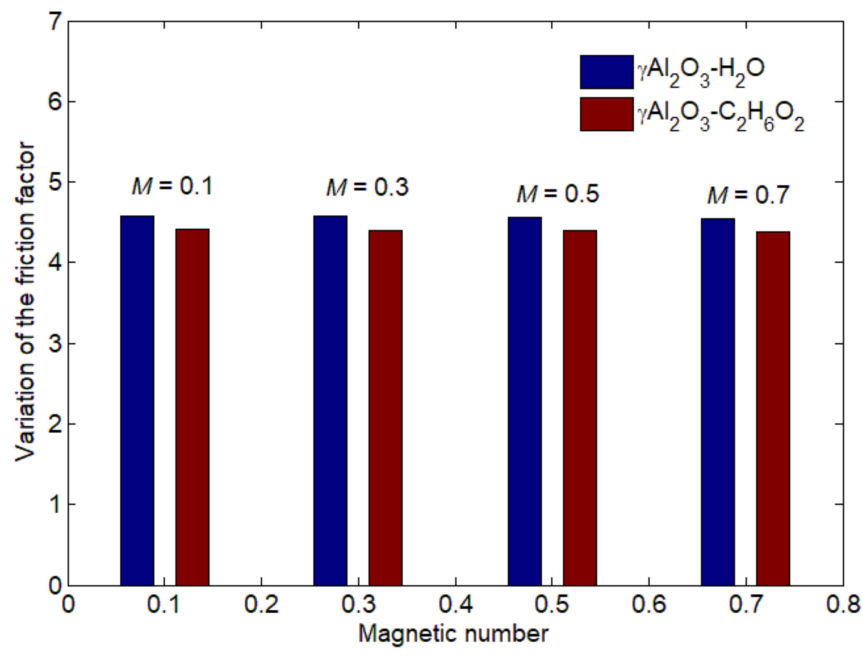

Figure 17. Impact of $M$ on the friction factor.

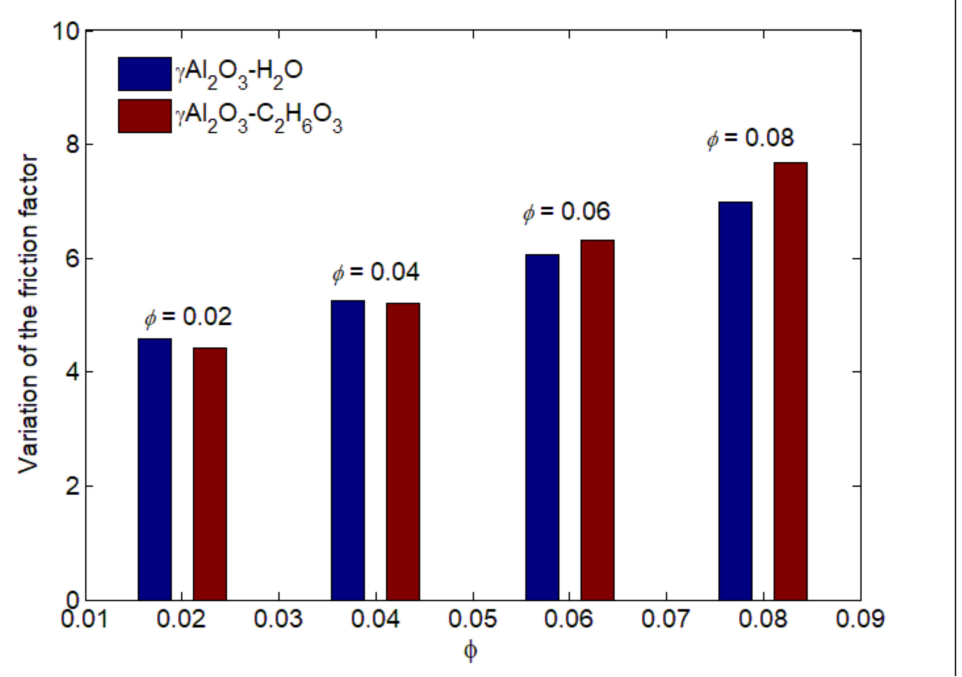

Figure 18. Impact of $\phi$ on the friction factor. 


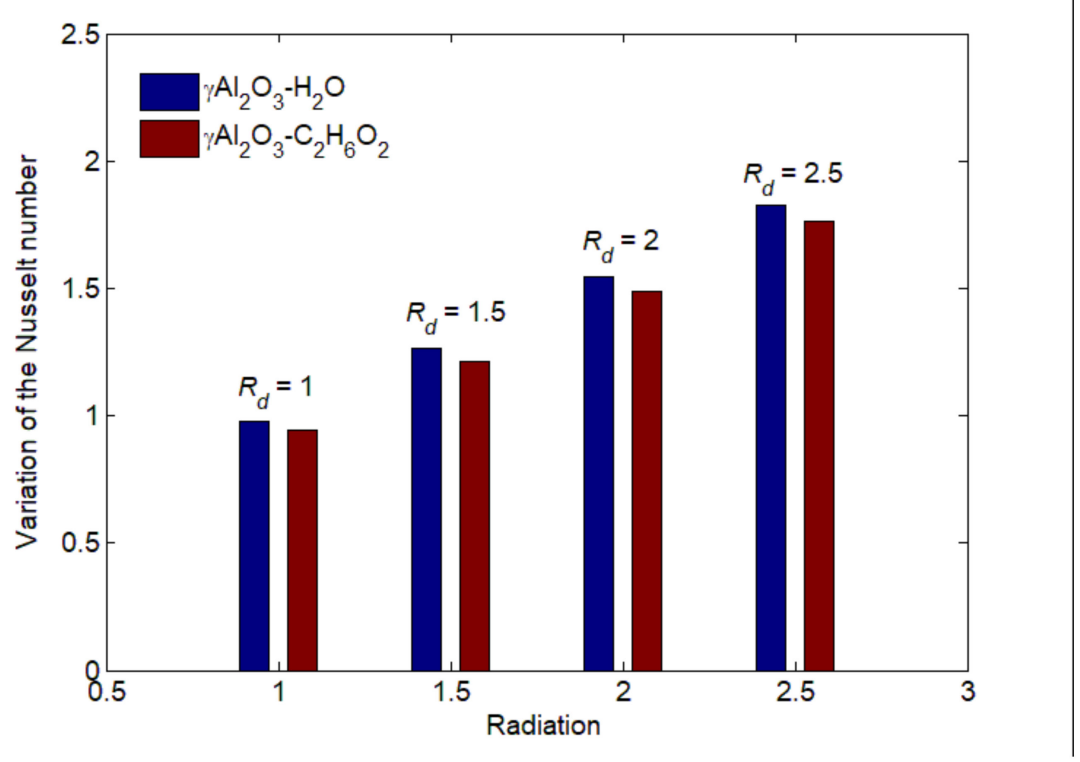

Figure 19. Impact of $R_{d}$ on the Nusselt number.

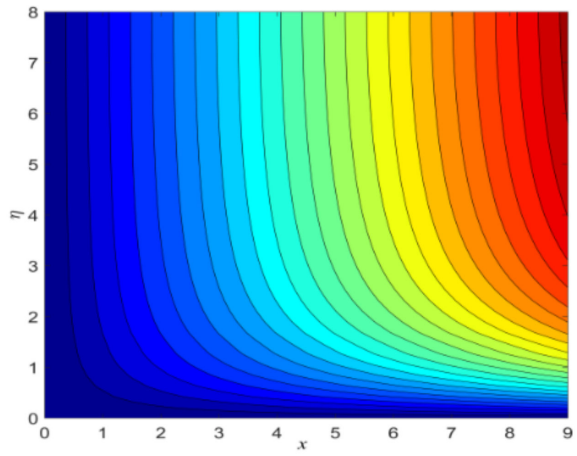

(a)

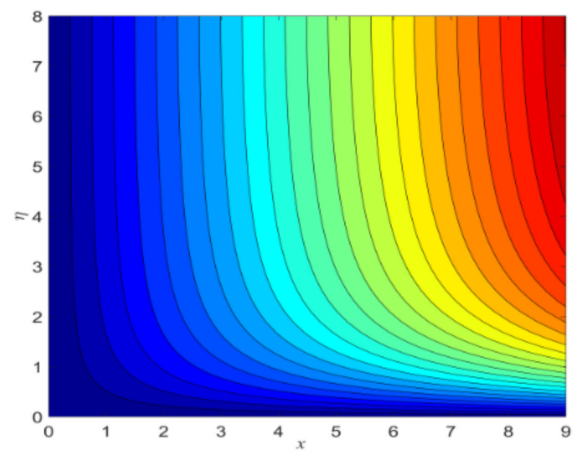

(b)

Figure 20. The streamline patterns for (a) $\gamma \mathrm{Al}_{2} \mathrm{O}_{3}-\mathrm{H}_{2} \mathrm{O}$ and (b) $\gamma \mathrm{Al}_{2} \mathrm{O}_{3}-\mathrm{C}_{2} \mathrm{H}_{6} \mathrm{O}_{2}$.

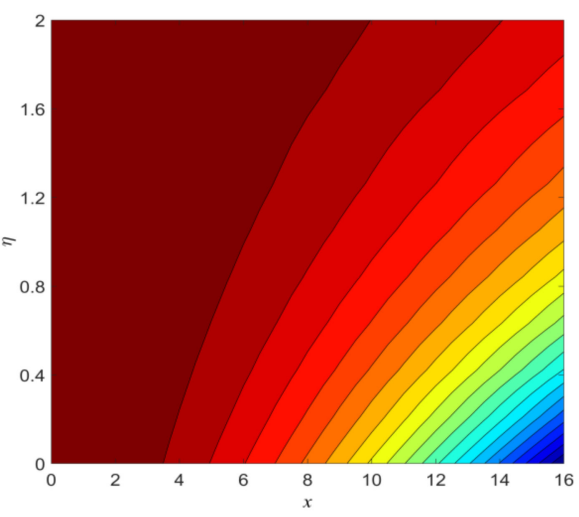

(a)

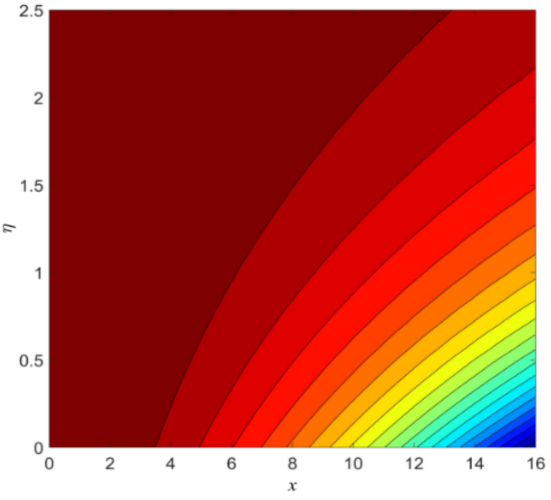

(b)

Figure 21. The isotherm patterns for (a) $\gamma \mathrm{Al}_{2} \mathrm{O}_{3}-\mathrm{H}_{2} \mathrm{O}$ and (b) $\gamma \mathrm{Al}_{2} \mathrm{O}_{3}-\mathrm{C}_{2} \mathrm{H}_{6} \mathrm{O}_{2}$.

The trend of significant parameters versus $\operatorname{Re}_{x}^{0.5} C_{F}$ and $\operatorname{Re}_{x}^{-0.5} N u_{x}$ for $\gamma \mathrm{Al}_{2} \mathrm{O}_{3}-$ $\mathrm{C}_{2} \mathrm{H}_{6} \mathrm{O}_{2}$ and $\gamma \mathrm{Al}_{2} \mathrm{O}_{3}-\mathrm{H}_{2} \mathrm{O}$ is seen in Tables 6 and 7 . 
Table 6. The numerical values of $-\operatorname{Re}_{x}^{0.5} C_{F}$ when $\lambda=0.1$.

\begin{tabular}{ccccc}
\hline $\boldsymbol{M}$ & $\boldsymbol{\phi}$ & $\boldsymbol{\varepsilon}$ & $\gamma \mathbf{A l}_{2} \mathbf{O}_{3}-\mathbf{H}_{2} \mathbf{O}$ & $\gamma \mathbf{A l}_{2} \mathbf{O}_{3}-\mathbf{C}_{2} \mathbf{H}_{6} \mathbf{O}_{2}$ \\
\hline 0.1 & 0.02 & 20 & 4.5829845 & 4.4160221 \\
\hline 0.3 & & 4.5707333 & 4.4041249 \\
\hline 0.5 & & 4.5584526 & 4.3921989 \\
\hline 0.7 & & 4.5461423 & 4.3802439 \\
\hline 1.0 & 0.02 & 20 & 4.5276209 & 4.3622570 \\
\hline 0.1 & 0.04 & 4.5829845 & 4.4160221 \\
\hline & 0.06 & 5.2573609 & 5.2056061 \\
\hline 0.08 & & 6.0648884 & 6.3245067 \\
\hline 0.1 & 0.02 & 6.9803698 & 7.6700892 \\
\hline & 10 & 7.9850461 & 9.1769811 \\
\hline & 20 & 3.3254211 & 3.2044599 \\
\hline & 30 & 4.5829845 & 4.4160221 \\
\hline & 40 & 5.5632504 & 5.3605209 \\
\hline & 50 & 6.3949900 & 6.1619350 \\
\hline
\end{tabular}

Table 7. The numerical values of $\operatorname{Re}_{x}^{-0.5} N u_{x}$ when $\lambda=0.1$.

\begin{tabular}{|c|c|c|c|c|c|c|c|c|c|}
\hline$R_{d}$ & $E c$ & $\xi$ & $\overline{\theta_{w}}$ & $\phi$ & $\varepsilon$ & $A_{0}$ & $B_{0}$ & $\gamma \mathrm{Al}_{2} \mathrm{O}_{3}-\mathrm{H}_{2} \mathrm{O}$ & $\gamma \mathrm{Al}_{2} \mathrm{O}_{3}-\mathrm{C}_{2} \mathrm{H}_{6} \mathrm{O}_{2}$ \\
\hline 01 & 0.5 & 0.5 & 01 & 0.02 & 20 & 0.1 & 0.1 & 0.979491227 & 0.941840165 \\
\hline 1.5 & & & & & & & & 1.26149515 & 1.21399674 \\
\hline 02 & & & & & & & & 1.54320424 & 1.48697783 \\
\hline 2.5 & & & & & & & & 1.8244553 & 1.76065943 \\
\hline 3 & & & & & & & & 2.10515155 & 2.03495597 \\
\hline \multirow[t]{5}{*}{01} & 0.3 & 0.5 & 01 & 0.02 & 20 & 0.1 & 0.1 & 1.03436938 & 1.02798261 \\
\hline & 0.5 & & & & & & & 0.979491227 & 0.941840165 \\
\hline & 0.7 & & & & & & & 0.924639087 & 0.85574787 \\
\hline & 1.0 & & & & & & & 0.842404491 & 0.726703157 \\
\hline & 1.5 & & & & & & & 0.70546786 & 0.511879004 \\
\hline \multirow[t]{2}{*}{01} & 0.5 & 0.5 & & & & & & 0.979491227 & 0.941840165 \\
\hline & & 0.7 & & & & & & 1.34834268 & 1.31435685 \\
\hline \multirow[t]{3}{*}{-} & - & 0.9 & & & & & & 1.70505352 & 1.68449696 \\
\hline & & 1.1 & & & & & & 2.05020822 & 2.05228348 \\
\hline & & 1.3 & & & & & & 2.38436703 & 2.41773846 \\
\hline 01 & 0.5 & 0.5 & 01 & 0.02 & 20 & 0.1 & 0.1 & 0.979491227 & 0.941840165 \\
\hline \multirow[t]{4}{*}{-} & - & - & 1.5 & & & & & 1.12509328 & 1.11333832 \\
\hline & & & 2.0 & & & & & 1.29538442 & 1.27500857 \\
\hline & & & 2.5 & & & & & 1.4938953 & 1.46547383 \\
\hline & & & 3.0 & & & & & 1.72502842 & 1.81713438 \\
\hline
\end{tabular}


Table 7. Cont.

\begin{tabular}{|c|c|c|c|c|c|c|c|c|c|}
\hline$R_{d}$ & $E c$ & $\xi$ & $\theta_{w}$ & $\phi$ & $\varepsilon$ & $A_{0}$ & $B_{0}$ & $\gamma \mathrm{Al}_{2} \mathrm{O}_{3}-\mathrm{H}_{2} \mathrm{O}$ & $\gamma \mathrm{Al}_{2} \mathrm{O}_{3}-\mathrm{C}_{2} \mathrm{H}_{6} \mathrm{O}_{2}$ \\
\hline \multirow[t]{5}{*}{01} & 0.5 & 0.5 & 01 & 0.02 & 20 & 0.1 & 0.1 & 0.979491227 & 0.941840165 \\
\hline & & & & 0.04 & & & & 0.966302546 & 0.923406415 \\
\hline & & & & 0.06 & & & & 0.952597644 & 0.909005851 \\
\hline & & & & 0.08 & & & & 0.939634672 & 0.899736613 \\
\hline & & & & 0.10 & & & & 0.927963377 & 0.894148357 \\
\hline \multirow[t]{5}{*}{01} & 0.5 & 0.5 & 01 & 0.02 & 10 & 0.1 & 0.1 & 0.962640123 & 0.937765787 \\
\hline & & & & & 20 & & & 0.979491227 & 0.941840165 \\
\hline & & & & & 30 & & & 0.98737614 & 0.943605729 \\
\hline & & & & & 40 & & & 0.992183202 & 0.944638809 \\
\hline & & & & & 50 & & & 0.995503652 & 0.945338938 \\
\hline \multirow[t]{5}{*}{01} & 0.5 & 0.5 & 01 & 0.02 & 20 & 0.1 & 0.1 & 0.979491227 & 0.941840165 \\
\hline & & & & & & 0.3 & 0.3 & 0.9788224 & 0.941810969 \\
\hline & & & & & & 0.5 & 0.5 & 0.978152778 & 0.94178177 \\
\hline & & & & & & 0.7 & 0.7 & 0.97748236 & 0.941752571 \\
\hline & & & & & & 0.9 & 0.9 & 0.976811145 & 0.941723371 \\
\hline \multirow[t]{5}{*}{01} & 0.5 & 0.5 & 01 & 0.02 & 20 & -0.1 & -0.1 & 0.980159261 & 0.941869361 \\
\hline & & & & & & -0.3 & -0.3 & 0.980826503 & 0.941898555 \\
\hline & & & & & & -0.5 & -0.5 & 0.981492955 & 0.941927748 \\
\hline & & & & & & -0.7 & -0.7 & 0.982158618 & 0.94195694 \\
\hline & & & & & & -0.9 & -0.9 & 0.982823494 & 0.94198613 \\
\hline
\end{tabular}

In addition, bar diagrams are also shown in Figures 17-19.

It is concluded from these observations that the larger values of $M$ subdued the friction factor in both nanofluids. The major reason is that MF capitulates the flow of nanofluids through the surface of the sheet owing to the prominent magnetic impact, which subdues the friction factor. In addition, the friction factor increases owing to the $\phi$ in both nanofluids. In the water-based $\gamma-\mathrm{Al}_{2} \mathrm{O}_{3}$ nanofluid, the values of the skin factor are greater compared to the ethylene-based $\gamma-\mathrm{Al}_{2} \mathrm{O}_{3}$ nanofluid, due to the superior thermal diffusivity. Moreover, the Nusselt number increases with the radiation due to fact that the radiation generates superior molecular force in the flow, while the opposite trend is explored due to the Eckert number. Both the Nusselt number and the friction factor increase due to the time-dependent parameter. The streamlines and isotherms are plotted in Figure 20a,b and Figure 21a,b.

\section{Conclusions}

In this article we examined the time-dependent flow for an effective Prandtl model of $\gamma$ nanofluids from a stretched sheet. Mixed convection, nonlinear radiation and viscous dissipation were analyzed. The significant findings are listed below:

- $\quad$ Both profiles of velocity and the temperature increase owing to $\phi$ for $\gamma \mathrm{Al}_{2} \mathrm{O}_{3}-$ $\mathrm{H}_{2} \mathrm{O} \backslash \mathrm{C}_{2} \mathrm{H}_{6} \mathrm{O}_{2}$ nanofluids.

- The velocity increases due to the assisting flow and decline in the opposing flow for $\gamma \mathrm{Al}_{2} \mathrm{O}_{3}-\mathrm{H}_{2} \mathrm{O} \backslash \mathrm{C}_{2} \mathrm{H}_{6} \mathrm{O}_{2}$ nanofluids, while the reverse trend is seen for temperature.

- The magnetic function decreases the velocity and increases the temperature distribution.

- The temperature of nanofluids increases due to radiation, Eckert, heat source and convective parameters, while the temperature decreases due to the heat sink. 
- The EG increases due to $\mathrm{Re}_{L}, \phi$ and $\mathrm{Br}$ for $\gamma \mathrm{Al}_{2} \mathrm{O}_{3}-\mathrm{C}_{2} \mathrm{H}_{6} \mathrm{O}_{2}$ and $\gamma \mathrm{Al}_{2} \mathrm{O}_{3}-\mathrm{H}_{2} \mathrm{O}$ nanofluids.

- The influence of ethylene-glycol-based $\gamma-\mathrm{Al}_{2} \mathrm{O}_{3}$ nanofluids on the temperature is lesser compared to water-based $\gamma-\mathrm{Al}_{2} \mathrm{O}_{3}$ nanofluids.

- The friction factor decreases due to $M$ and increases due to $\phi$ in both nanofluids.

- The Nusselt number increases due to $R_{d}$ and declines due to $E c$ in both nanofluids.

- The time-dependent parameter increases the Nusselt number as well as the friction factor.

Author Contributions: Conceptualization, A.Z. and I.K.; methodology, U.K.; software, U.K.; validation, K.S.N., I.K. and U.K.; formal analysis, A.Z.; investigation, U.K.; resources, I.K.; data curation, U.K.; writing-original draft preparation, A.Z.; writing-review and editing, I.K.; visualization, K.S.N.; supervision, K.S.N.; project administration, I.K.; funding acquisition, K.S.N. All authors have read and agreed to the published version of the manuscript.

Funding: The authors did not receive any specific funding for this work.

Data Availability Statement: Data is contained within the article.

Conflicts of Interest: The authors declare that there is no conflict of interest regarding the publication of this paper.

\section{References}

1. Crane, L.J. Flow past a stretching plate. Zeitschrift für angewandte Mathematik und Physik 1970, 21, 645-647. [CrossRef]

2. Afzal, N.; Varshney, I.S. The cooing of a low heat resistance stretching sheet moving through a fluid. Warme Stoffubertrag 1980, 14, 289-293. [CrossRef]

3. Ali, M.E. Heat transfer characteristics of a continuous stretching surface. Heat Mass Transf. 1994, 29, 227-234. [CrossRef]

4. Andersson, H.; Bech, K.; Dandapat, B. Magnetohydrodynamic flow of a power-law fluid over a stretching sheet. Int. J. Non-linear Mech. 1992, 27, 929-936. [CrossRef]

5. Magyari, E.; Keller, B. Exact solutions for self-similar boundary-layer flows induced by permeable stretching walls. Eur. J. Mech.-B/Fluids 2000, 19, 109-122. [CrossRef]

6. Sparrow, E.M.; Abraham, J.P. Universal solutions for the streamwise variation of the temperature of a moving sheet in the presence of a moving fluid. Int. J. Heat Mass Transf. 2005, 48, 3047-3056. [CrossRef]

7. Abraham, J.P.; Sparrow, E.M. Friction drag resulting from the simultaneous imposed motions of a free stream and its bounding surface. Int. J. Heat Fluid Flow 2005, 26, 289-295. [CrossRef]

8. Ishak, A.; Nazar, R.; Pop, I. Boundary layer flow and heat transfer over an unsteady stretching vertical surface. Meccanica 2008, 44, 369-375. [CrossRef]

9. Zaib, A.; Sharidan, S. Thermal diffusion and diffusion thermo effects on unsteady MHD free convection flow over a stretching surface considering Joule heating and viscous dissipation with thermal stratification, chemical reaction and Hall current. $J$. Franklin Inst. 2004, 351, 1268-1287. [CrossRef]

10. Choi, S.U.S. Enhancing thermal conductivity of fluids with nanoparticles. In Proceedings of the ASME International Mechanical Engineering Congress and Exposition, San Francisco, CA, USA, 12-17 November 1995; pp. 99-105.

11. Sheikholeslami, M.; Mustafa, M.T.; Ganji, D.D. Effect of Lorentz forces on forced convection nanofluid flow over a stretched surface. Particuology 2016, 26, 108-113. [CrossRef]

12. Mutuku, W.N.; Makinde, O.D. Double stratification effects on heat and mass transfer in unsteady MHD nanofluid flow over a flat surface. Asia Pac. J. Comput. Eng. 2017, 4. [CrossRef]

13. Khan, N.S.; Gul, T.; Islam, S.; Khan, I.; Alqahtani, A.M.; Alshomrani, A.S. Magneto-hydrodynamic nanoliquid thin film sprayed on a stretching cylinder with heat transfer. Appl. Sci. 2017, 7, 271. [CrossRef]

14. Gireesha, B.; Mahanthesh, B.; Thammanna, G.; Sampathkumar, P. Hall effects on dusty nanofluid two-phase transient flow past a stretching sheet using KVL model. J. Mol. Liq. 2018, 256, 139-147. [CrossRef]

15. Soomro, F.A.; Zaib, A.; Haq, R.U.; Sheikholeslami, M. Dual nature solution of water functionalized copper nanoparticles along a permeable shrinking cylinder: FDM approach. Int. J. Heat Mass Transf. 2019, 129, 1242-1249. [CrossRef]

16. Mahanthesh, B.; Lorenzini, G.; Oudina, F.M.; Animasaun, I.L. Significance of exponential space- and thermal-dependent heat source effects on nanofluid flow due to radially elongated disk with Coriolis and Lorentz forces. J. Therm. Anal. Calorim. 2019, 141, 37-44. [CrossRef]

17. Eid, M.R. Effects of NP Shapes on Non-Newtonian Bio-Nanofluid Flow in Suction/Blowing Process with Convective Condition: Sisko Model. J. Non-Equilibrium Thermodyn. 2020, 45, 97-108. [CrossRef]

18. Khan, W.A.; Ali, M.; Shahzad, M.; Sultan, F.; Irfan, M.; Asghar, Z. A note on activation energy and magnetic dipole aspects for Cross nanofluid subjected to cylindrical surface. Appl. Nanosci. 2019, 10, 3235-3244. [CrossRef] 
19. Kumar, P.B.S.; Gireesha, B.J.; Mahanthesh, B.; Chamkha, A.J. Thermal analysis of nanofluid flow containing gyrotactic microorganisms in bioconvection and second-order slip with convective condition. J. Therm. Anal. Calorim. 2019, 136, $1947-1957$. [CrossRef]

20. Kumar, K.G.; Rahimi-Gorji, M.; Reddy, M.G.; Chamkha, A.J.; Alarifi, I.M. Enhancement of heat transfer in a convergent/divergent channel by using carbon nanotubes in the presence of a Darcy-Forchheimer medium. Microsyst. Technol. 2019, 26, 323-332. [CrossRef]

21. Maïga, S.E.B.; Nguyen, C.T.; Galanis, N.; Roy, G. Heat transfer behaviours of nanofluids in a uniformly heated tube. Superlattices Microstruct. 2004, 35, 543-557. [CrossRef]

22. Maiga, S.E.B.; Nguyen, C.T.; Galanis, N.; Roy, G.C. Micro and nano heat transfer heat transfer enhancement in forced convection laminar tube flow by using nanofluids. In Proceedings of the CHT-04-Advances in Computational Heat Transfer III. Proceedings of the Third International Symposium, Begell House, Danbury, CT, USA, 2004; p. 24.

23. Maïga, S.E.B.; Palm, S.J.; Nguyen, C.T.; Roy, G.; Galanis, N. Heat transfer enhancement by using nanofluids in forced convection flows. Int. J. Heat Fluid Flow 2005, 26, 530-546. [CrossRef]

24. Pop, C.V.; Fohanno, S.; Polidori, G.; Nguyen, C.T. Analysis of laminar-to-turbulent threshold with water $\gamma \mathrm{Al} 2 \mathrm{O} 3$ and ethylene glycol- $\gamma \gamma \mathrm{Al} 2 \mathrm{O} 3$ nanofluids in free convection. In Proceedings of the 5th IASME/WSEAS Int. Conference on Heat Transfer, Thermal Engineering and Environment, Athens, Greece, 25-27 August 2007; p. 188.

25. Farajollahi, B.; Etemad, S.; Hojjat, M. Heat transfer of nanofluids in a shell and tube heat exchanger. Int. J. Heat Mass Transf. 2010, 53, 12-17. [CrossRef]

26. Sow, T.M.O.; Halelfadl, S.; Lebourlout, S.; Nguyen, C.T. Experimental study of the freezing point of $\gamma$-Al2O3water nanofluid. Adv. Mech. Eng. 2012, 4, 162961. [CrossRef]

27. Maciver, D.S.; Tobin, H.H.; Barth, R.T. Catalytic aluminas I. Surface chemistry of eta and gamma alumina. J. Catal. 1963, 2, 487-497. [CrossRef]

28. Rashidi, M.M.; Ganesh, N.V.; Hakeem, A.K.A.; Ganga, B.; Lorenzini, G. Influences of an effective Prandtl number model on nano boundary layer flow of $\gamma \mathrm{Al} 2 \mathrm{O} 3-\mathrm{H} 2 \mathrm{O}$ and $\gamma \mathrm{A} 12 \mathrm{O} 3-\mathrm{C} 2 \mathrm{H} 6 \mathrm{O} 2$ over a vertical stretching sheet. Int. J. Heat Mass Transf. 2016, 98, 616-623. [CrossRef]

29. Ganesh, N.V.; Hakeem, A.A.; Ganga, B. A comparative theoretical study on $\mathrm{Al} 2 \mathrm{O} 3$ and $\gamma-\mathrm{Al} 2 \mathrm{O} 3$ nanoparticles with different base fluids over a stretching sheet. Adv. Powder Technol. 2016, 27, 436-441. [CrossRef]

30. Moghaieb, H.S.; Abdel-Hamid, H.M.; Shedid, M.H.; Helali, A.B. Engine cooling using $\gamma \mathrm{Al} 2 \mathrm{O} 3 /$ water nanofluids. Appl. Therm. Eng. 2017, 115, 152-159. [CrossRef]

31. Ahmed, N.; Adnan; Khan, U.; Mohyud-Din, S.T. A theoretical investigation of unsteady thermally stratified flow of $\gamma \mathrm{Al} 2 \mathrm{O} 3-\mathrm{H} 2 \mathrm{O}$ and $\gamma \mathrm{Al} 2 \mathrm{O} 3-\mathrm{C} 2 \mathrm{H} 6 \mathrm{O} 2$ nanofluids through a thin slit. J. Phys. Chem. Solids 2018, 119, 296-308. [CrossRef]

32. Zaib, A.; Haq, R.; Sheikholeslami, M.; Khan, U. Numerical analysis of effective Prandtl model on mixed convection flow of $\gamma \mathrm{Al} 2 \mathrm{O} 3-\mathrm{H} 2 \mathrm{O}$ nanoliquids with micropolar liquid driven through wedge. Phys. Scr. 2019, 95, 035005. [CrossRef]

33. Bejan, A. Entropy Generation Minimization: The Method of Thermodynamic Optimization of Finite-Size Systems and Finite-Time Processes, 1st ed.; CRC Press; Taylor \& Francis: Boca Raton, FL, USA; ISBN 97814987829201996.

34. Bejan, A. A Study of Entropy Generation in Fundamental Convective Heat Transfer. J. Heat Transf. 1979, 101, 718-725. [CrossRef]

35. Ko, T.; Ting, K. Optimal Reynolds number for the fully developed laminar forced convection in a helical coiled tube. Energy 2006, 31, 2142-2152. [CrossRef]

36. Hajmohammadi, M.R.; Lorenzini, G.; Shariatzadeh, O.J.; Biserni, C. Evolution in the Design of V-Shaped Highly Conductive Pathways Embedded in a Heat-Generating Piece. J. Heat Transf. 2015, 137, 061001. [CrossRef]

37. Xie, G.; Song, Y.; Asadi, M.; Lorenzini, G. Optimization of Pin-Fins for a Heat Exchanger by Entropy Generation Minimization and Constructal Law. J. Heat Transf. 2015, 137, 061901. [CrossRef]

38. Lorenzini, G.; Moretti, S. Bejan's Constructal theory and overall performance assessment: The global optimization for heat exchanging finned modules. Therm. Sci. 2014, 18, 339-348. [CrossRef]

39. Abouzar, P.; Hajmohammadi, M.R.; Sadegh, P. Investigations on the internal shape of constructal cavities intruding a heat generating body. Therm. Sci. 2015, 19, 609-618.

40. Hajmohammadi, M.R.; Campo, A.; Nourazar, S.S.; Ostad, A.M. Improvement of Forced Convection Cooling Due to the Attachment of Heat Sources to a Conducting Thick Plate. J. Heat Transf. 2013, 135, 124504. [CrossRef]

41. Govindaraju, M.; Ganesh, N.V.; Ganga, B.; Hakeem, A.A. Entropy generation analysis of magneto hydrodynamic flow of a nanofluid over a stretching sheet. J. Egypt. Math. Soc. 2015, 23, 429-434. [CrossRef]

42. Rashidi, M.; Abelman, S.; Mehr, N.F. Entropy generation in steady MHD flow due to a rotating porous disk in a nanofluid. Int. J. Heat Mass Transf. 2013, 62, 515-525. [CrossRef]

43. Dalir, N.; Dehsara, M.; Nourazar, S.S. Entropy analysis for magnetohydrodynamic flow and heat transfer of a Jeffrey nanofluid over a stretching sheet. Energy 2015, 79, 351-362. [CrossRef]

44. Shit, G.C.; Haldar, R.; Mandal, S. Entropy generation on MHD flow and convective heat transfer in a porous medium of ex-ponentially stretching surface saturated by nanofluids. Adv. Powder Tech. 2017, 28, 1519-1530. [CrossRef]

45. Hayat, T.; Khana, M.I.; Qayyuma, S.; Alsaedi, A. Entropy generation in flow with silver and copper nanoparticles. Colloids Surfaces 2018, 539, 335-346. [CrossRef] 
46. Shafee, A.; Jafaryar, M.; Alsabery, A.I.; Zaib, A.; Babazadeh, H. Entropy generation of nanomaterial through a tube considering swirl flow tools. J. Therm. Anal. Calorim. 2020, 1-16. [CrossRef]

47. Ganesh, N.V.; Chamkha, A.J.; Al-Mdallal, Q.M.; Kameswaran, P.K. Magneto-Marangoni nano-boundary layer flow of water and ethylene glycol based $\gamma \mathrm{Al} 2 \mathrm{O} 3$ nanofluids with non-linear thermal radiation effects. Case Stud. Thermal Eng. 2018, 12, 340-348.

48. Makinde, O.D.; Olanrewaju, P.O. Buoyancy Effects on Thermal Boundary Layer Over a Vertical Plate With a Convective Surface Boundary Condition. J. Fluids Eng. 2010, 132, 044502. [CrossRef]

49. Shafie, S.; Mahmood, T.; Pop, I. Similarity solutions for the unsteady boundary layer flow and heat transfer due to a stretching sheet. Int. J. Appl. Mech. Eng. 2006, 11, 647-654.

50. Chamkha, A.J.; Aly, A.M.; Mansour, M.A. Similarity solution for unsteady heat and mass transfer from a stretching surface embedded in a porous medium with suc-tion/injection and chemical reaction effects. Chem. Eng. Commun. 2010, 197, 846-858. [CrossRef] 